\title{
PROCEDIMIENTO PARA SELECCIÓN DE ACELEROGRAMAS PARA ESTUDIOS DE FRAGILIDAD EN PUENTES TÍPICOS DE ARGENTINA
}

\author{
José A. Saracho ${ }^{(1)(2)}$, Gustavo A. Perez ${ }^{(2)}$ y Oscar Dip ${ }^{(1)(2)}$
}

\begin{abstract}
RESUMEN
Los acelerogramas adoptados para realizar estudios de fragilidad en puentes a través de análisis dinámico no lineal son uno de los componentes de mayor influencia en los resultados obtenidos. El objetivo de este trabajo es presentar una metodología para selección y escalado de acelerogramas reales de sismos registrados en distintas partes del mundo en ambientes tectónicos semejantes a los del centro-oeste argentino, de manera tal de contar con series de registros compatibles con espectros para distintas clases de sitio, zonas de peligrosidad sísmica y niveles de amenaza sísmica. Para ello, se hizo uso de la aplicación web de la base de datos de movimientos sísmicos del PEER (Pacific Earthquake Engineering Research Center's). Se tomaron en consideración los espectros objetivos y distintos parámetros, tales como: magnitud del sismo, tipo de falla, distancia de la estructura a la falla, velocidad media de la onda de corte en los 30 metros superiores del terreno, etc. Mediante la aplicación de un criterio novedoso, en el cual se contempla la Intensidad de Aceleración Espectral (ASI), se arribó a 16 series de sismos considerando: 4 clases de sitio, zonas de elevada y muy peligrosidad sísmica del territorio nacional y periodos de recurrencia de 500 y 2500 años. Estas series de registros representativas de la sismicidad de la región referida podrán utilizarse luego para obtener curvas de fragilidad de mayor confiabilidad para distintas clases de puentes típicos.
\end{abstract}

Palabras clave: acelerogramas; fragilidad; vulnerabilidad sísmica; puentes; Argentina

\section{PROCEDURE FOR SELECTION OF ACCELEROGRAMS FOR FRAGILITY STUDIES IN TYPICAL BRIDGES OF ARGENTINA}

\begin{abstract}
The accelerograms adopted to perform fragility studies in bridges through non-linear dynamic analysis are one of the components with the greatest influence on the results obtained. The objective of this paper is to present a methodology for the selection and scaling of real accelerograms of earthquakes recorded in different parts of the world in tectonic environments similar to those of the Argentine central-west, in order to have series of records compatible with spectra for different site classes, seismic hazard zones and seismic hazard levels. For this, the web application of the PEER
\end{abstract}

Artículo recibido el 29 de diciembre de 2019 y aprobado para su publicación el 06 de diciembre de 2021. Se aceptarán comentarios y/o discusiones hasta cinco meses después de su publicación.

(1) Departamento de Ingeniería Civil, Facultad Regional Tucumán, Universidad Tecnológica Nacional, Rivadavia 1050, 4000, San Miguel de Tucumán, Tucumán, Argentina. joseanibalsaracho@yahoo.com.ar

(2) Instituto de Estructuras Ing. Arturo M. Guzmán, Facultad de Ciencias Exactas y Tecnología, Universidad Nacional de Tucumán, Av. Independencia 1800, 4000, San Miguel de Tucumán, Tucumán, Argentina. gperez@herrera.unt.edu.ar; odip@ herrera.unt.edu.ar

DOI: $10.18867 /$ ris. 106.553 
(Pacific Earthquaque Engineering Research Center) seismic ground motion database was used. The target spectrum and different parameters were taken into consideration, such as: magnitude of the earthquake, type of faulting, distance of the structure to the fault, site shear wave velocity in the upper 30 meters, etc. Through the application of a novel criterion, in which the Spectral Acceleration Intensity (ASI) is considered, 16 series of earthquakes were reached considering: 4 classes of site, areas of high and very dangerous seismic in the national territory and recurrence periods 500 and 2500 years. These series of records representative of the seismicity of the referred region can then be used to obtain fragility curves of greater reliability for different classes of typical bridges.

Keywords: accelerograms; fragility; seismic vulnerability; bridges; Argentina

\section{INTRODUCCIÓN}

El daño sísmico reportado después de sismos importantes ocurridos en los últimos años (Loma Prieta en 1989, Northridge en 1994, Kobe en 1995, Kocaeli en 1999, Taiwan en 1999, Tecomán en 2003, Cachemira en 2005, L' Aquila en 2009, Honduras en 2009, Haití en 2010, Chile en 2010 y Japón en 2011) ha vuelto a poner de manifiesto que los puentes son los componentes críticos de los sistemas de transporte. Al salir de servicio un puente se producen interrupciones significativas de las redes de transporte, ocasionando grandes pérdidas económicas indirectas. Asimismo, la necesidad de mantener operativas dichas redes para la atención de la emergencia luego de la ocurrencia del evento sísmico indica la importancia de que los puentes permanezcan en estado operacional, o de que al menos tengan función parcial y que la total sea restablecida en tiempos mínimos. Para comprobar este desempeño se debe verificar la aptitud estructural de los puentes ante la acción sísmica, con lo cual se podrán caracterizar los sistemas más susceptibles mediante determinaciones de su vulnerabilidad. Una vez realizado esto, se podrán establecer prioridades y pautas relacionadas con la necesidad de rehabilitación, refuerzo o reemplazo de las estructuras más comprometidas.

Para evaluar la vulnerabilidad sísmica de puentes puede seguirse un camino determinístico o bien abordar un método probabilístico. En este último caso se tienen en cuenta la aleatoriedad e incertidumbres de los parámetros que afectan a la capacidad y a la demanda sísmica. En este sentido, en los últimos tiempos se ha popularizado el uso de un procedimiento que caracteriza la naturaleza probabilística de estos fenómenos, denominado "Curvas de fragilidad".

Concretamente, las curvas de fragilidad representan la probabilidad acumulada de que una estructura exceda un determinado estado de daño en función de un parámetro que define la intensidad sísmica. En específico, dichas curvas constituyen relaciones entre la acción sísmica y el daño para cierta clase de puentes. A modo de ejemplo, en figura 1 se ofrecen las curvas de fragilidad obtenidas por Nielson (2005) para puentes de hormigón armado de múltiples tramos en zonas de moderada peligrosidad sísmica de los Estados Unidos. En abscisas se representan valores de la aceleración máxima del terreno (PGA por sus siglas en ingles), expresados como fracción de la aceleración de la gravedad, mientras que en ordenadas, la probabilidad acumulada de exceder un determinado estado de daño. Cada una de las curvas de la figura corresponde a un determinado estado de daño, caracterizados como: leve, moderado, severo y total. 


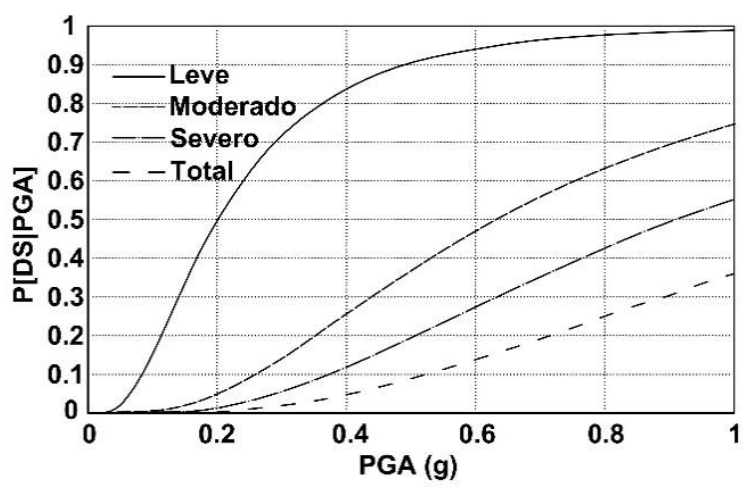

Figura 1. Curvas de Fragilidad para puentes típicos de hormigón armado en zona central de USA (Nielson, 2005)

Los movimientos del terreno por acción sísmica son uno de los componentes que tienen mayor influencia sobre el desarrollo de curvas de fragilidad analíticas. La variabilidad de los parámetros estructurales y sus modelos analíticos, las definiciones de los estados de daño y los parámetros de amenaza sísmica son las principales fuentes de incertidumbre consideradas en dichas curvas de Fragilidad (Avsar, 2009). En relación a esto, Kwon y Elnashai (2006) indicaron que el efecto de aleatoriedad en las características de los movimientos fuertes del terreno es mucho más pronunciado que el efecto de otras incertidumbres involucradas. La incertidumbre en la amenaza sísmica es abordada a través de la consideración de conjuntos de movimientos sísmicos que sean representativos de la sismicidad de la región donde los puentes se hallan ubicados. No obstante, no hay un método específico para la selección apropiada de tales conjuntos de movimientos sísmicos con los cuales ejecutar a posteriori análisis dinámicos no lineales en procura de la obtención de las citadas curvas de fragilidad. El principal propósito en la selección de movimientos del terreno es compilar conjuntos que generen un amplio rango de acciones sísmicas, de manera tal de imponer variados grados de daños sísmicos en los puentes. De darse esta situación, se puede proveer un número suficiente de datos con distribución uniforme a lo largo de las abscisas de las curvas de fragilidad. Por el contrario, si los sismos seleccionados imponen daños similares en los puentes, la variación en las demandas sísmicas, que se calculan a partir de la respuesta de los análisis dinámicos no lineales llevados a cabo, será limitada. En tal caso, los puntos sobre la curva de fragilidad pueden llegar a amontonarse para ciertos niveles de intensidad sísmica (Avsar, 2009).

\section{METODOLOGÍA}

En este trabajo se seleccionan varios registros sísmicos en una cantidad suficiente como para conformar conjuntos de datos de entrada para posteriores ejecuciones de análisis dinámicos no lineales. Con vistas a representar la variabilidad registro a registro en las curvas de fragilidad analíticas a construir, se consideran diferentes movimientos de terreno que cubren un amplio rango de niveles de amenaza sísmica. Las curvas de fragilidad dan información sobre el nivel de probabilidad de daño sísmico con respecto a distintos niveles de amenaza para las estructuras que pertenecen a una cierta región. No obstante, los movimientos sísmicos registrados en dicha región de estudio pueden no resultar adecuados o bien la variabilidad registro a registro puede que no esté representada con los datos disponibles. En tales situaciones, según Avsar (2009), en estudios previos se utilizaron acelerogramas sintéticos espectralmente compatibles (Elnashai et al., 2004; Nielson, 2005; Padgett y DesRoches, 2007). Dichos acelerogramas pueden desarrollarse usando modelos teóricos de movimientos del terreno que simulan el proceso de ruptura del sismo y la propagación de la onda a través de la corteza terrestre desde la fuente al sitio. Mientras estos registros sintéticos están forzados a ser compatibles con el espectro de diseño específico del sitio de estudio, 
es altamente posible obtener registros que tienen contenidos de energía y frecuencia no reales. Asimismo, los registros sintéticos típicamente acusan duración mayor en comparación con los reales (Priestley et al., 2007). Naeim y Lew (1995) mencionaron que puede haber problemas potenciales significativos asociados con el uso descontrolado de registros sintéticos provocando una exageración en el input de la demanda de desplazamiento y energía, lo cual podría distorsionar el desempeño esperado de la estructura cuando se halla expuesta a acción sísmica.

Por otro lado, en el aspecto normativo, en el Manual de Rehabilitación Sísmica de Puentes de la Administración Federal de Carreteras de los Estados Unidos FHWA (Buckle et al., 2006) se establece que resultan de preferencia acelerogramas registrados en sitios con similares características tectónicas, previéndose dos procedimientos para la selección y desarrollo de tales acelerogramas a emplearse en análisis dinámico no lineal. En el primer caso se trata de registros reales que son escalados por un factor constante, de manera tal que el espectro de respuesta se corresponda en promedio con el espectro de diseño en el rango de periodos de significancia estructural. En el segundo procedimiento, se parte del simple escalado como en el caso anterior para luego efectuar un ajuste más acabado del contenido de frecuencias también en el rango de significancia estructural. Asimismo, en el mismo Manual se ofrecen los requerimientos de compatibilidad para evaluar el ajuste.

En el estudio llevado a cabo por Tim Huff (2016) se emplearon tres estrategias para seleccionar y modificar un conjunto de movimientos sísmicos: 1) Escalado, 2) Ajuste en el dominio del tiempo y 3) Ajuste en el dominio de las frecuencias. Los resultados arrojaron que el ajuste en el dominio de las frecuencias puede tener un efecto dramático sobre los parámetros de los movimientos del terreno, con valores muy grandes de la duración significativa y mayores magnitudes de los desplazamientos respecto de los obtenidos mediante escalado, produciendo movimientos potencialmente no realistas. Por el contrario, en el caso de los registros ajustados en el dominio del tiempo se advierten valores menores de duración significativa como así también en los desplazamientos respecto de los obtenidos por medio del escalado; asimismo, se advierte una significativa subestimación del espectro inelástico de desplazamientos. Por su parte en el método de escalado, los efectos de duración y medidas de intensidad relativa entre los dos componentes de los registros son preservados, concluyéndose por ende que resulta de preferencia como procedimiento de modificación de movimientos del terreno.

En atención a lo indicado, en el presente estudio se aplicará el método de escalado de registros sísmicos reales que representen la sismicidad de la región investigada. Por ejemplo, este criterio se siguió para la selección de registros apropiados para la realización de estudios sísmicos en diversas ciudades de Taiwán (Huang et al., 2017).

El presente trabajo abarca la región centro-oeste de nuestro país, en zonas caracterizadas como de elevada y muy elevada peligrosidad símica. En procura del desarrollo de curvas de fragilidad para puentes de nuestro territorio, los autores realizaron una clasificación general de puentes, para lo cual se estudió la base de datos del Sistema de Gestión de Puentes de Vialidad Nacional, SIGMA PUENTES (Saracho et al., 2016). Asimismo, se hicieron estudios determinísticos de vulnerabilidad sísmica sobre dos puentes típicos correspondientes a dos de las citadas clases, los cuales se hallan ubicados en la provincia de Mendoza (Saracho et al., 2019).

\section{Características de las fuentes sismogénicas principales en la región de estudio}

Cabe destacar que los registros obtenidos de sismos pasados en Argentina no son suficientes para ser usados en el desarrollo de curvas de fragilidad para puentes. En general se dispone de muy poca información de esta clase, especialmente en regiones como la nuestra donde ocurren pocos terremotos fuertes y es difícil registrarlos por la baja densidad del instrumental de registro (Castano, 1992). Por lo tanto, se recurrirá a 
movimientos del terreno registrados en otras regiones que tienen similares mecanismos de falla y potencial sísmico respecto del centro-oeste argentino.

Los grandes terremotos de la región de estudio se han caracterizado por estar asociados a fallas activas que se encuentran próximas a importantes centros urbanos. La sismicidad está relacionada con terremotos superficiales intraplaca o corticales que dan origen a sismos tipo impulsivos o de fuente cercana como los registrados para el terremoto de Mendoza de 1985 (M=5.9) y San Juan 1977 (M=7.4) (Frau y Saragoni, 2005). Hay un predominio de fallas tipo inversas (Frau y Saragoni, 2005), aunque también existen fallas de desplazamiento de rumbo, ambas constituyendo fuentes sísmicas potenciales (Castano, 1992). Dichas fuentes potenciales de la actividad sísmica superficial se ubican en figura 2. Puede apreciarse el alineamiento de importantes fallas con los centros urbanos más densamente poblados. Nótese la situación de la ciudad de San Juan respecto de la falla "Precordillera Oriental" y la ciudad de Mendoza respecto de la falla "Cerro La Cal".

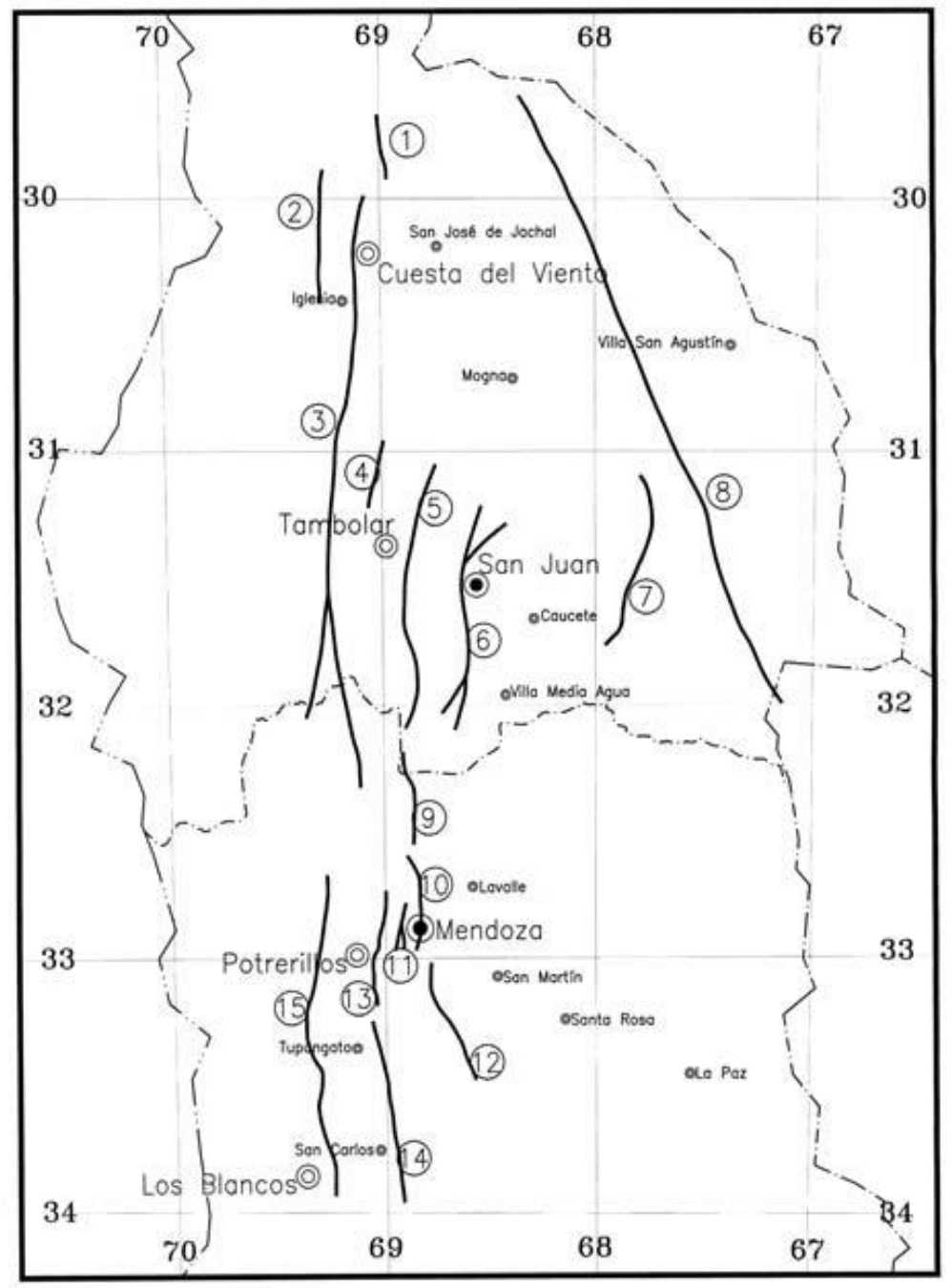

Figura 2. Ubicación de fuentes sismogénicas potenciales del centro-oeste argentino (Castano, 1992)

En la tabla 1, se resumen las características fundamentales de dichas fuentes sísmicas potenciales. Se destacan por su ubicación, magnitud y recurrencia las fallas de La Punilla-La Bolsa (Ms=7.6, 900 años), el 
Tigre (Ms=7.8, 1250 años), Precordillera Oriental (Ms=7.5, 400 años), Cerro La Cal (Ms=7.0, 1300 años), Barrancas (Ms=7.0, 600 años) y Tupungato (Ms=7.0, 1000 años). Asimismo, las zonas identificadas como Sureste San Juan (Ms=6.0, 200 años) y Noreste Mendoza (Ms=6.0, 200 años).

Tabla 1. Características fundamentales de fuentes sismogénicas principales del centro-oeste argentino (Castano, 1992)

\begin{tabular}{llccc}
\hline $\mathrm{N}^{\mathbf{0}}$ & \multicolumn{1}{c}{ Fuente sísmica } & \multicolumn{2}{c}{ Terremoto Potencial Máximo } & Terremoto Histórico \\
\cline { 3 - 4 } & \multicolumn{1}{c}{ Fallas } & $\begin{array}{c}\text { Magnitud } \\
\text { [Ms] }\end{array}$ & $\begin{array}{c}\text { Recurrencia } \\
\text { [años] }\end{array}$ & $\begin{array}{c}\text { Asociado } \\
\text { Fecha/Magnitud }\end{array}$ \\
\hline 1 & Punilla-La Bolsa (SJ) & 7.6 & 900 & 27 Oct. 1894, Ms=7.5 \\
2 & Pismanta (SJ) & 7.3 & 4000 & - \\
3 & El Tigre (SJ) & 7.8 & 1250 & - \\
4 & La Cantera (SJ) & 6.9 & 5000 & 19 Mar. 1924, Ms=6.2 \\
5 & Maradona-Deheza (SJ) & 7.3 & 8000 & 11 Jun. 1952, Ms=7.0 \\
6 & Precordillera Oriental (SJ) & 7.5 & 400 & 15 Ene. 1944, Ms=7.4 \\
7 & Ampacama (SJ) & 7.8 & 4000 & 23 Nov. 1977, Ms=7.4 \\
8 & Valle Fértil (SJ) & 7.0 & 3000 & - \\
9 & Los Cerrillos MZA) & 7.5 & 5000 & - \\
10 & Cerro La Cal (MZA) & 7.0 & 1300 & 20 Mar. 1861, Ms=7.0 \\
11 & Cerro de La Gloria (MZA) & 6.5 & 10000 & - \\
12 & Barrancas (MZA) & 7.0 & 600 & 26 Ene. 1985, Ms=5.9 \\
13 & Melocotón (MZA) & 7.0 & 4000 & 22 May. 1785, Ms=7.0 \\
14 & Tupungato (MZA) & 7.0 & 1000 & - \\
15 & Cordillera Frontal (MZA) & 7.7 & 5000 & - \\
& & & & \\
1 & Zubducción & 7.5 & 500 & 14 Abr. 1927, Ms=7.1 \\
2 & Sureste San Juan & 6.0 & 200 & - \\
3 & Noreste de Mendoza & 6.0 & 200 & 17 Dic. 1920, Ms=6.0 \\
4 & Chile Central & 8.5 & 100 & 11 Nov. 1922, Ms=8.4 \\
\hline
\end{tabular}

\section{Herramienta utilizada para la selección. Definición de espectros objetivos}

Según Huang et al. (2017), muchos estudios han resaltado la importancia de alcanzar un espectro objetivo en los procesos de selección y modificación de registros de movimientos del terreno, por ejemplo, el trabajo de Bommer y Acevedo (2004). Se entiende por espectro objetivo, aquel al que deben aproximarse cada uno de los espectros de los registros seleccionados. Estos espectros objetivos se pueden obtener por medio de análisis de amenaza sísmica por la vía determinística, probabilística, o bien a partir de los brindados en los códigos de diseño sísmico. Este último, será el camino a seguir en este estudio.

Siguiendo a Huang et al. (2017), hay diversos algoritmos de selección de movimientos del terreno disponibles en la literatura (Baker, 2010; Jayaram et al., 2011; Wang, 2011). Una de las herramientas propuestas más versátiles lo constituye la aplicación web de la base de datos de movimientos del terreno del PEER (Pacific Earthquake Engineering Research Center's) - Next Generation Attenuation (NGA). La misma permite seleccionar una serie de registros modificados (multiplicados por factores de escala) sobre la base de compatibilizar la forma espectral de cada uno de los registros respecto del espectro objetivo. En el proceso de selección, también se toman en consideración parámetros tales como la magnitud del sismo, tipo y distancia a la falla, características del sitio, duración y presencia de pulsos de velocidad en el caso de registros de fuente cercana (Wang et al., 2015). Esta base de datos, que contiene 3551 registros en las tres componentes de 173 sismos intraplaca (Chiou y Youngs, 2008), constituirá la fuente para seleccionar los acelerogramas en este estudio. En la figura 3 se ofrece una vista de esta especie de formulario electrónico correspondiente a la aplicación web del PEER - NGA (www.ngawest2.berkeley.edu). Mayores detalles 
sobre el uso de esta aplicación web pueden consultarse en el correspondiente Manual del Usuario (PEER, 2010a).
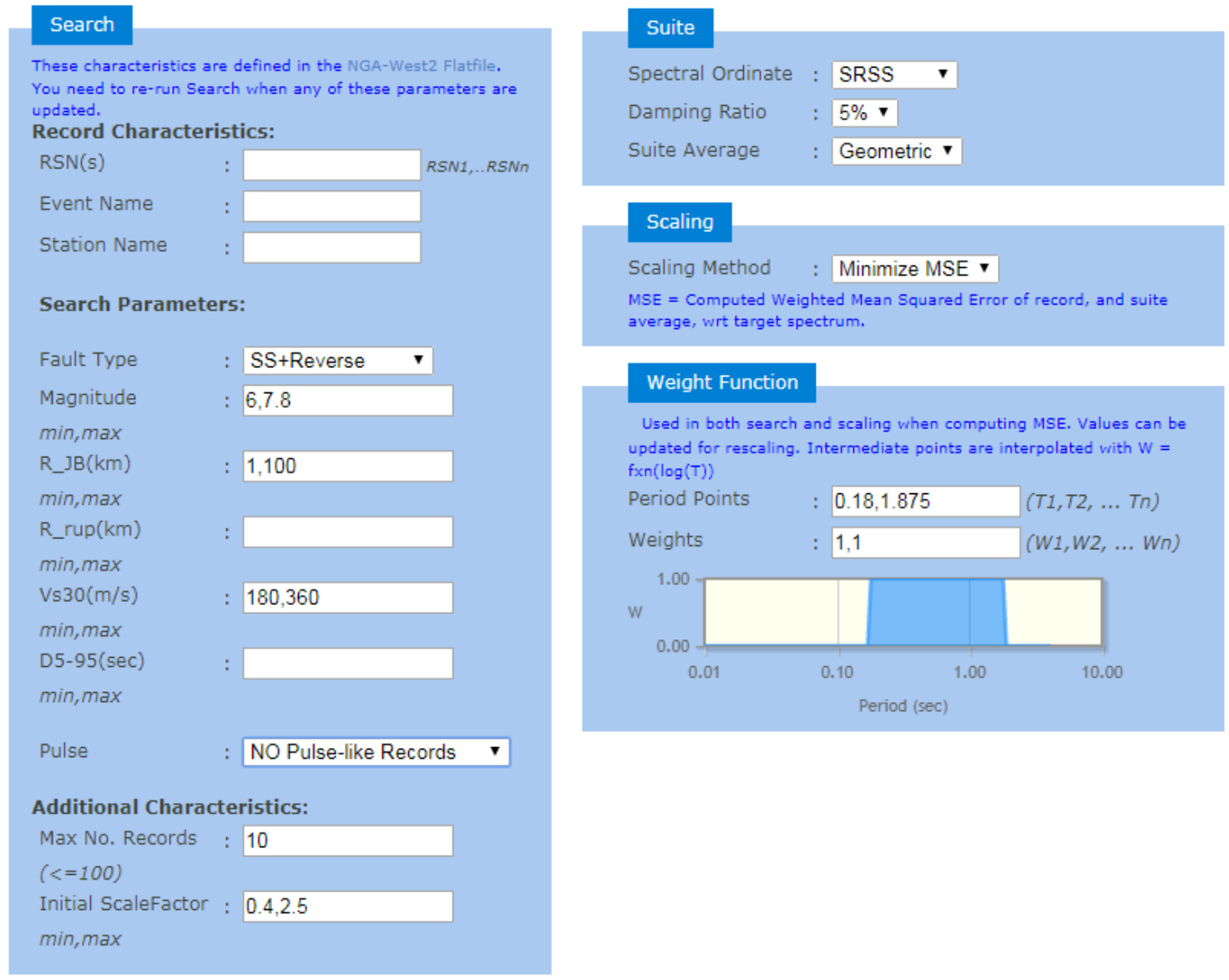

Figura 3. Aplicación web de la base de datos del PEER-NGA

Mediante la utilización de la herramienta presentada se obtendrán dos series de movimientos sísmicos. Cada serie se corresponde a dos niveles distintos de amenaza sísmica, expresados como la probabilidad de excedencia del movimiento sísmico durante la vida útil promedio de los puentes, considerada de 75 años según AASHTO (2018). Ver tabla 2.

Tabla 2. Series de movimientos sísmicos

\begin{tabular}{ccc}
\hline $\mathrm{N}^{\mathrm{o}}$ de Serie & $\begin{array}{c}\text { Probabilidad de excedencia en la vida útil del } \\
\text { puente }(75 \text { años })\end{array}$ & $\begin{array}{c}\text { Periodo de Retorno aproximado } \\
{[\% \text { [Anos] }}\end{array}$ \\
\hline 1 & 15 & 500 \\
2 & 3 & 2500 \\
\hline
\end{tabular}

Estos dos niveles de amenaza sísmica también fueron tomados en consideración en otros estudios, de manera de proveer acelerogramas para ulteriores análisis estructurales. Por ejemplo, en el estudio llevado a cabo para el área de Seattle (SAC, 1997). Asimismo, en el correspondiente a la zona central y sudeste de los Estados Unidos, Ciudades de Memphis, Carbondale y St. Louis (Wen y Wu, 2001). También, en aquel realizado para un conjunto de localidades en Canadá, conforme al espectro de riesgo uniforme dado por el 
Código de diseño de edificaciones (Atkinson, 2009). Igualmente, en el inherente a los movimientos específicos de sitio para Oakland, California (Baker et al., 2011)

Para cada una de las series de registros, se consideraron también las distintas clases de sitio fijadas en el Reglamento Argentino para Construcciones Sismorresistentes, Parte VI Puentes de Hormigón Armado (INPRES-CIRSOC 103, 2019). Allí se establecen, para cada una de dichas clases, los rangos de la velocidad media de la onda de corte en los 30 metros superiores del terreno $\left(\mathrm{V}_{\mathrm{s} 30}\right)$, los cuales representan un indicador de la condición de sitio. Ver tabla 3.

Tabla 3. Velocidad media de la onda de corte en los $30 \mathrm{~m}$ superiores del terreno

\begin{tabular}{clc}
\hline Sitio & Descripción del perfil de suelos & $\begin{array}{c}\text { Velocidad media de la onda de } \\
\text { corte } \mathrm{V}_{\mathrm{s} 30}[\mathrm{~m} / \mathrm{seg}]\end{array}$ \\
\hline $\mathrm{S}_{\mathrm{A}}$ & $\begin{array}{l}\text { Formación de roca dura, con presencia superficial y escasa } \\
\text { meteorización }\end{array}$ & 7600 \\
$\mathrm{~S}_{\mathrm{B}}$ & $\begin{array}{l}\text { Formación de roca dura con pequeña capa de suelo denso y/o } \\
\text { roca meteorizada < 3m }\end{array}$ & $360-760$ \\
$\mathrm{~S}_{\mathrm{C}} \quad \begin{array}{l}\text { Formación de roca blanda o meteorizada que no cumple con } \mathrm{S}_{\mathrm{A}} \\
\text { y } \mathrm{S}_{\mathrm{B} .} \text { Gravas y/o arenas muy densas. Suelo cohesivo pre- }\end{array}$ & $\begin{array}{l}\text { consolidado, muy duro. Gravas y/o arenas de densidad media. } \\
\mathrm{S}_{\mathrm{D}}\end{array}$ & $\begin{array}{l}\text { Suelo cohesivo consistente, de baja plasticidad. Gravas y/o } \\
\text { arenas de baja densidad. }\end{array}$ \\
$\mathrm{S}_{\mathrm{E}}$ & Suelo cohesivo blando de baja plasticidad. & $180-360$ \\
\hline
\end{tabular}

El Reglamento anteriormente citado (INPRES-CIRSOC 103, 2019), que está basado en las especificaciones AASHTO para el diseño sísmico de puentes (AASHTO, 2011), ofrece los distintos parámetros del espectro de diseño conforme a las distintas clases de sitio y zonas de peligrosidad sísmica. Dicho espectro se corresponde con el denominado sismo de diseño, para un periodo de retorno de aproximadamente 1000 años.

Para la obtención de los espectros de diseño de las series 1 y 2, que constituyen los espectros objetivos para la búsqueda de registros, se empleará el criterio de aplicar factores de reducción y amplificación, respectivamente, sobre los espectros de diseño obtenidos según lo indicado en el párrafo anterior. En este sentido se tuvieron en consideración distintos estudios que se tomaron como referencia. Tal el caso de "Espectros sísmicos de riesgo uniforme para verificar desempeño estructural en países latinoamericanos" (Aguiar Falconi, 2003), en el que se presenta una propuesta para encontrar formas espectrales para los sismos denominados como frecuente, ocasional, raro y muy raro, según el comité VISION 2000. Así, por ejemplo, las ordenadas espectrales del sismo de 1000 años de recurrencia, muy raro, se obtienen de multiplicar por 1.3 las del de 500 años, raro. A su vez, en la normativa para la Rehabilitación Sísmica de Edificios de la Agencia Federal de Gestión de la Emergencia de los Estados Unidos (FEMA 356, 2000) se establece que las ordenadas espectrales correspondientes a una amenaza sísmica con periodo de retorno de 500 años, sismo de diseño en edificaciones, equivalen a $2 / 3$ de las correspondientes a 2500 años, sismo máximo considerado. Por ende, aplicando este criterio, los espectros para 2500 años pueden obtenerse de multiplicar por 1.5 las ordenadas espectrales del de 500 años. Por otro lado, en el Manual de Evaluación y Rehabilitación Sísmica de Puentes de la FHWA (Buckle et al., 2006) se establecen para distintas ciudades de California relaciones entre las ordenadas espectrales que corresponden al periodo de retorno de 2500 años con respecto a las de 500 años, para periodo corto $(0.2 \mathrm{~s})$ y periodo largo $(1 \mathrm{~s})$. En ambos casos estas relaciones oscilan entre 1.2 y 1.7. Por su parte, en el trabajo sobre "Perfil de Riesgo de Desastres para Argentina", elaborado por el Centro Internacional de Métodos Numéricos en Ingeniería-CIMNE- (Cardona et al., 2016), en el apartado evaluación probabilista del riesgo sísmico, se brindan espectros de amenaza uniforme para diferentes periodos de retorno para algunas ciudades ubicadas en zonas la elevada y muy elevada peligrosidad sísmica del territorio nacional, entre ellas Mendoza y San Juan. Analizando los espectros para dichas ciudades, se obtuvo, en promedio, una relación de aproximadamente 1.57 entre las 
ordenadas espectrales correspondientes a los dos periodos de retorno, 2500 y 500 años. Tal relación se halla muy próxima a la establecida en FEMA 356 (2000) y está dentro del rango establecido en FHWA (Buckle et al., 2006). Finalmente, dada la mayor pertinencia, operando con resultados del estudio citado del CIMNE (Cardona et al., 2016) se obtuvieron los coeficientes buscados: 1.24 para la relación promedio entre las ordenadas espectrales correspondientes a 1000 años de recurrencia respecto de las de 500 y 1.27 para la relación entre las ordenadas de 2500 años respecto de las de 1000. También puede apreciarse la proximidad entre el primer coeficiente, 1.24, respecto del derivado de la propuesta de Aguiar Falconí, 1.30.

Por último, considerando las zonas sísmicas 3 y 4 (elevada y muy elevada peligrosidad, respectivamente) conforme a lo establecido en la Parte I del Reglamento Argentino de Construcciones Sismorresistentes (INPRES CIRSOC 103, 2018), con las cinco clases de sitio para cada una de ellas según INPRES CIRSOC 103 (2019), se tienen diez espectros para cada uno de los dos niveles de amenaza sísmica. Lo que hace un total de veinte espectros objetivos para la búsqueda. En el mapa de la figura 4 se indica la zonificación sísmica de la república Argentina. A modo ilustrativo, en figuras 5 y 6 se ofrecen los espectros que corresponden a la zona sísmica 4, para las cinco clases de sitio y con niveles de amenaza sísmica de 500 y 2500 años respectivamente.

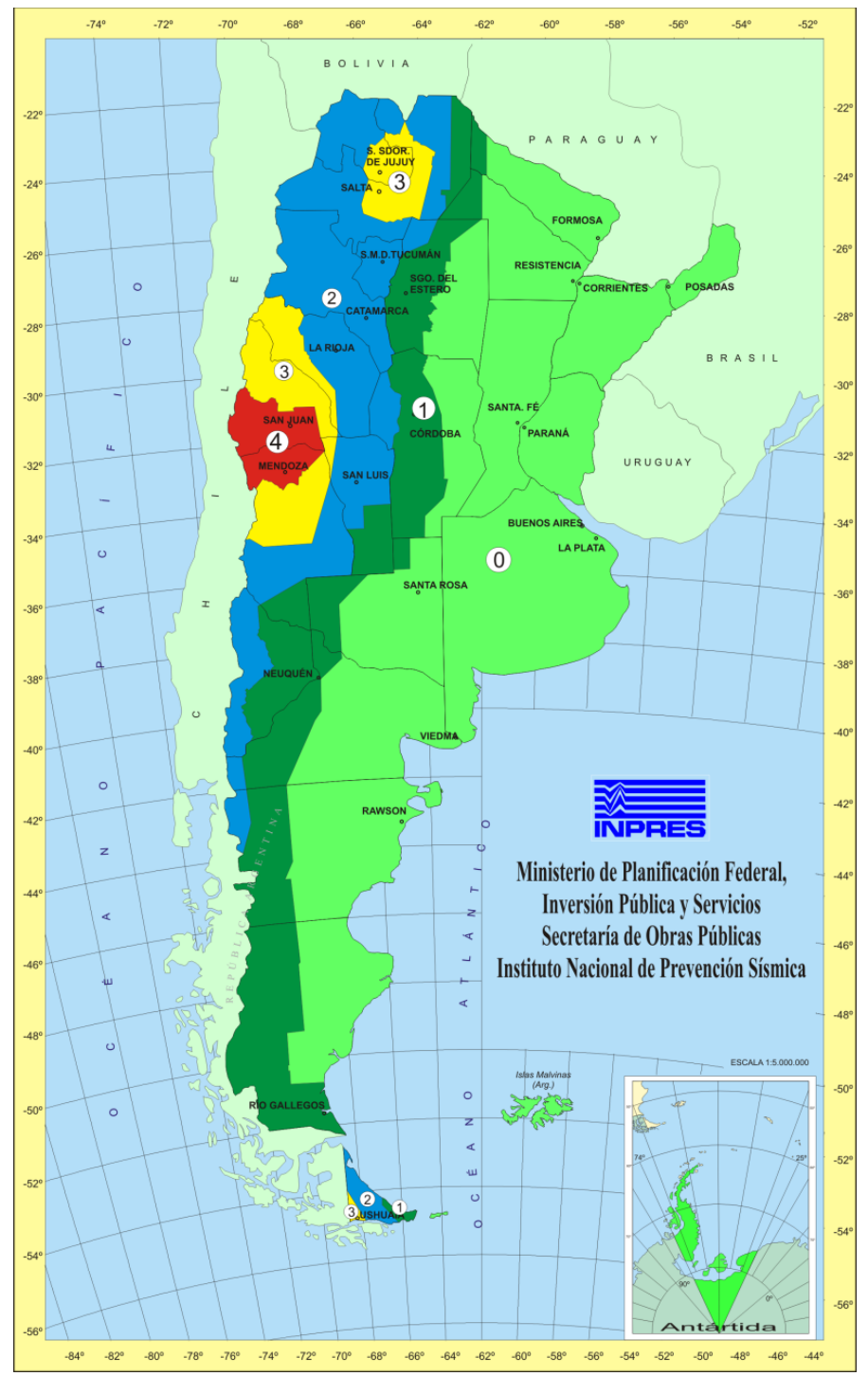

Figura 4. Zonificación sísmica de la República Argentina (INPRES CIRSOC 103, 2018) 


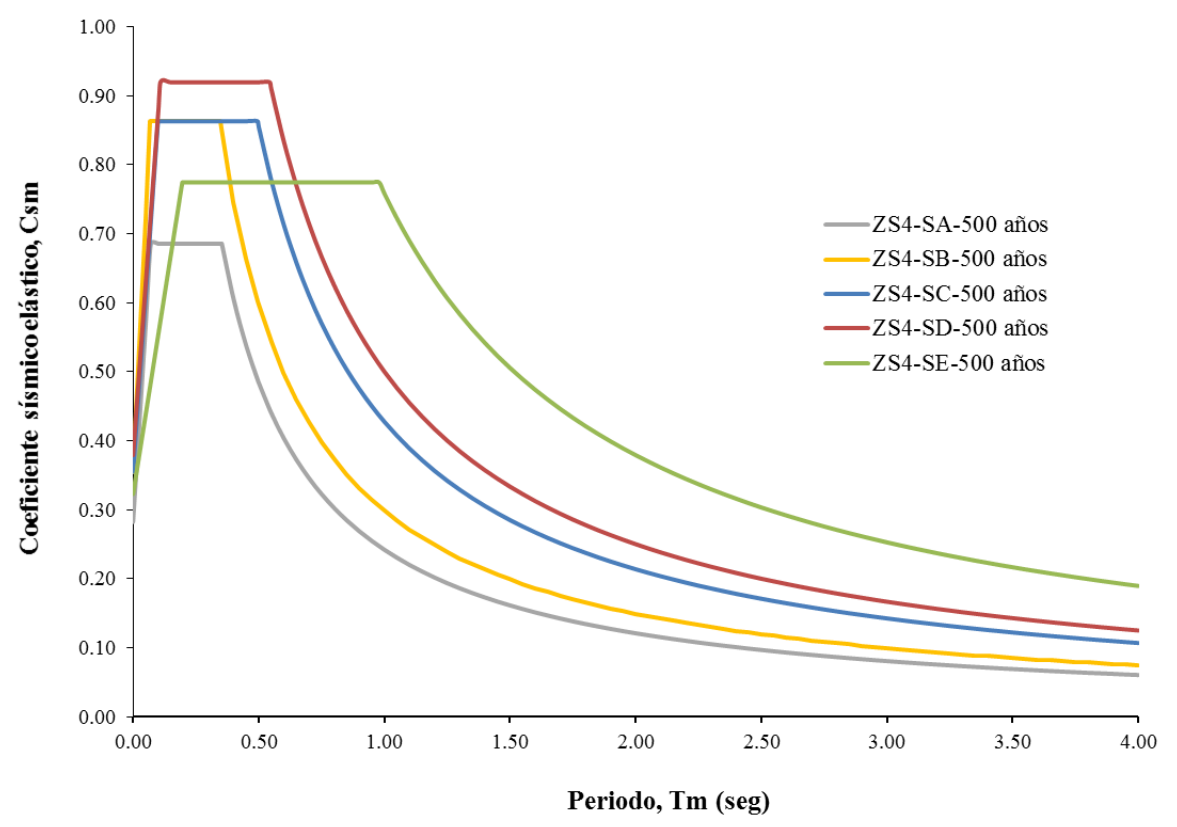

$\bar{w}$
$\tilde{N}$
1
0
$\tilde{\omega}$
0
0
0
0
$N$
$心$
$\omega$

Figura 5. Espectros elásticos para zona sísmica 4 y nivel de amenaza sísmica de 500 años de recurrencia

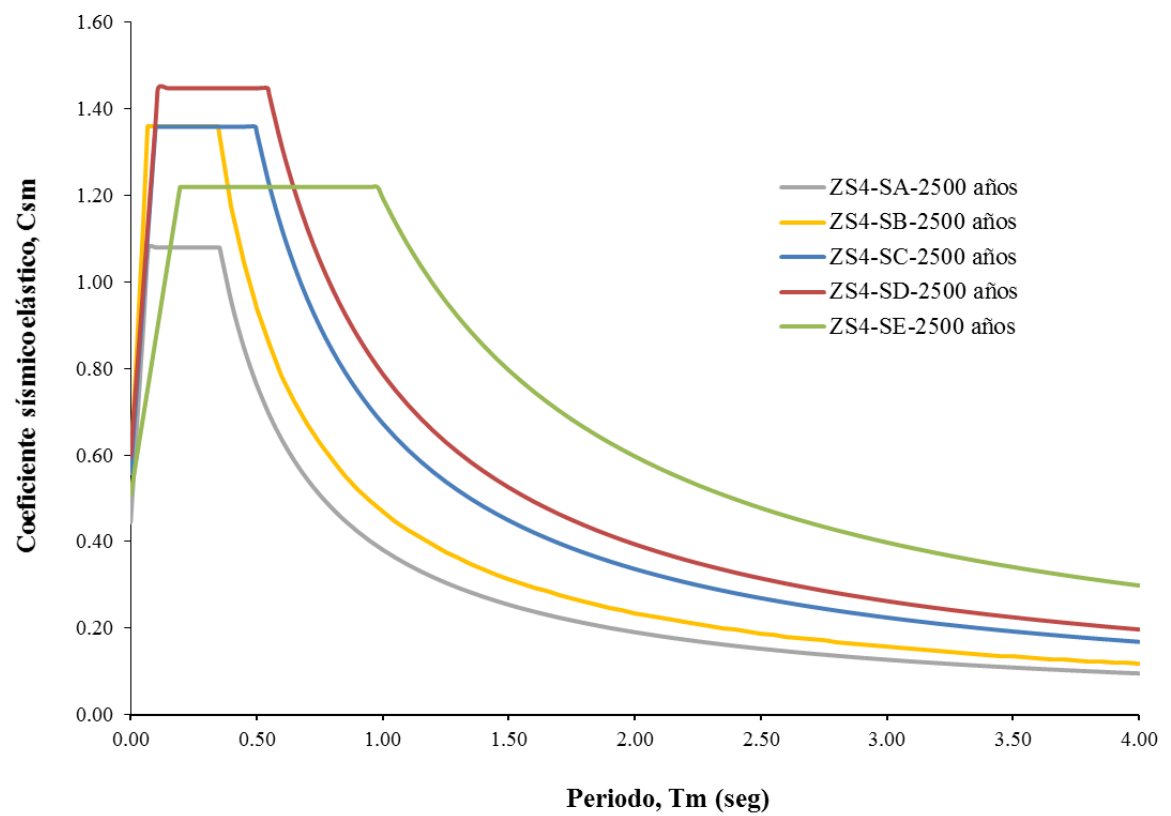

Figura 6. Espectros elásticos para zona sísmica 4 y nivel de amenaza sísmica de 2500 años de recurrencia 


\section{Criterios adoptados para la búsqueda de acelerogramas}

Según se mencionó, además de los espectros objetivos, para orientar la búsqueda son requeridos parámetros sismológicos de entrada, tales como rangos de Magnitud y Distancia, entre otros. Respecto de ello, es importante destacar que dada la ausencia de un estudio de desagregación de la amenaza sísmica para la región de interés, mediante el cual se determinen las contribuciones predominantes de magnitud y distancia, se toman en consideración los resultados de estudios llevados a cabo en regiones tectónicas similares, con terremotos intraplaca o corticales. Tal el caso de los estudios para Canadá (Atkinson, 2009) y Estados Unidos (Harmsen y Frenkel, 2001). Tanto en estos trabajos, como en el Manual de Rehabilitación Sísmica de Puentes FHWA (Buckle et al., 2006) y en las disposiciones de FEMA (FEMA P-751, 2012), se establece que sismos cercanos de pequeña a moderada magnitud dominan en el rango de periodos cortos del espectro, en tanto que sismos distantes y de gran magnitud prevalecen en el rango de periodos largos.

En el estudio de Atkinson (2009) para lugares del Este de Canadá, se toman en consideración Magnitudes momento de 6, con rangos de distancia entre 10 y $30 \mathrm{~km}$, y de 7, con distancias entre 15 y 100 $\mathrm{km}$. En tanto que para el oeste, una Magnitud de 6.5 con distancias entre 10 y $30 \mathrm{~km}$ y otra magnitud de 7.5 , con distancias entre 15 y $100 \mathrm{~km}$.

Asimismo, merece citarse el trabajo de Rix y Fernandez (2004), en el cual se generaron sismos artificiales para la ciudad de Memphis, Tennessee. Allí se conformaron duplas de Magnitud momento (Mw) - Distancias (R), mediante la combinación de los siguientes valores asumidos para tales parámetros: Mw: 5.5, 6.5, 7.5 y R: $10 \mathrm{~km}, 20 \mathrm{~km}, 50 \mathrm{~km}, 100 \mathrm{~km}$.

En atención a las características fundamentales de las fuentes sísmicas potenciales localizadas en la región de estudio (ver Figura 2 y Tabla 1), el rango de magnitudes para la búsqueda de registros será adoptado entre 6 y 7.8. En tanto para las distancias, se tomarán los valores entre $1 \mathrm{~km} \mathrm{y} 100 \mathrm{~km}$, rango que cubre las fuentes cercanas a intermedias. Esto se hizo con motivo de que las distancias mayores, correspondientes a fuentes lejanas, afectan a las estructuras de periodo largo, las cuales están fuera del alcance de este estudio. Esto se constató en el estudio de Atkinson (2009) donde, para zonas de subducción en el oeste (Cascadia), se simuló un evento de Magnitud 9 con rangos de distancia de 100 a $200 \mathrm{~km}$, dando como resultado acelerogramas de gran duración y con rico contenido de energía para periodos grandes.

Otro parámetro para la búsqueda lo constituyen los tipos de falla. En este caso se indicarán fallas inversas y de rumbo, ya que ambas constituyen fuentes sísmicas potenciales según se señaló.

En relación a la velocidad media de la onda de corte en los 30 metros superiores del terreno $\left(\mathrm{V}_{\mathrm{s} 30}\right)$, se ingresarán los rangos de valores presentados en Tabla 3, en función de la clase de sitio asumida.

El factor de escala es otro de los puntos clave en la entrada de datos para la selección de movimientos del terreno. Diversas investigaciones previas mostraron que el inapropiado escalado de un registro podía llevar a estimaciones sesgadas de la respuesta estructural (Luco y Cornell, 2007). Por ejemplo, si se aplica un excesivo rango de valores para los factores de escala, la serie de registros seleccionados podría resultar en una distribución marcadamente sesgada respecto de otras características de los movimientos del terreno, tales como la Duración y la Intensidad de Arias, las cuales no pueden ser representadas por el espectro objetivo. Por lo tanto, para el procedimiento de selección, en este trabajo asignamos un rango estrecho para los factores de escala, entre 0.4 y 2.5 según las recomendaciones de Wang et al. (2015) (Huang et al., 2017).

Otro aspecto decisivo, es la definición del rango de periodo de significancia estructural en el cual se debe verificar el mejor ajuste entre las ordenadas espectrales de los registros obtenidos respecto del espectro objetivo. La medida cuantitativa usada en la aplicación web para este propósito es el error cuadrático medio 
de la diferencia entre las citadas ordenadas espectrales. En el siguiente apartado se darán detalles sobre la obtención de este rango de periodos.

Para tener un panorama completo, se realizaron dos grandes instancias de búsqueda. En la primera se especificó como criterio adicional, la condición de diez registros del tipo no impulsivo, mientras que en la segunda, otros diez registros solo del tipo impulsivo. Este último criterio, se adoptó para disponer en la muestra total de un número suficiente de registros con pulsos de velocidad.

Como resultado, se obtuvo una muestra total de 274 registros, de los cuales 116 son del tipo impulsivo. A través de un proceso de clasificación y selección, que se explicará en el siguiente apartado, se obtendrán distintas series de registros, lo cual constituye el propósito de este estudio.

\section{Criterios adoptados para la selección final de conjuntos de acelerogramas por clase de sitio}

Según Avsar (2009), la aceleración máxima a que un puente es expuesto durante un sismo puede determinarse a partir de la ordenada del espectro elástico de respuesta que corresponde a su periodo fundamental. La máxima aceleración es proporcional a la fuerza sísmica impuesta, así como al daño sísmico que los puentes pueden experimentar. Por lo tanto, la aceleración espectral correspondiente al periodo fundamental del puente puede considerarse como una buena medida de intensidad para la estimación del daño sísmico. No obstante, los efectos de los modos más altos y el aumento del periodo fundamental a consecuencia de la respuesta inelástica de la estructura ejercen a su vez marcada influencia sobre el nivel de aceleración en los puentes. Esto lleva a la hipótesis de que no es conveniente considerar solamente un periodo para calcular la aceleración espectral. Más aún, las curvas de fragilidad son desarrolladas para distintas tipologías de puentes cuyos periodos fundamentales varían dentro de un rango determinado. Por lo tanto, será más razonable considerar un rango de periodos sobre el espectro de respuesta en lugar de tratar simplemente con un único valor de periodo. En tal sentido, se establece una magnitud que tiene en cuenta este aspecto. Se trata de la Intensidad de Aceleración Espectral (ASI por sus siglas en ingles), definida como el área bajo el espectro de respuesta elástico con 5\% de amortiguamiento entre de los periodos límites $\mathrm{T}_{\mathrm{i}} \mathrm{y}$ $\mathrm{T}_{\mathrm{f}}$, cuyo valor puede calcularse usando la ecuación (1).

$$
A S I=\int_{T_{i}}^{T_{f}} S A(T, \xi) d T
$$

donde $\mathrm{T}_{\mathrm{i}}$ y $\mathrm{T}_{\mathrm{f}}$ son definidos como los periodos inicial y final, respectivamente, a ser usados en el cálculo de ASI. Una representación gráfica de esta magnitud se ofrece en la figura 7. 


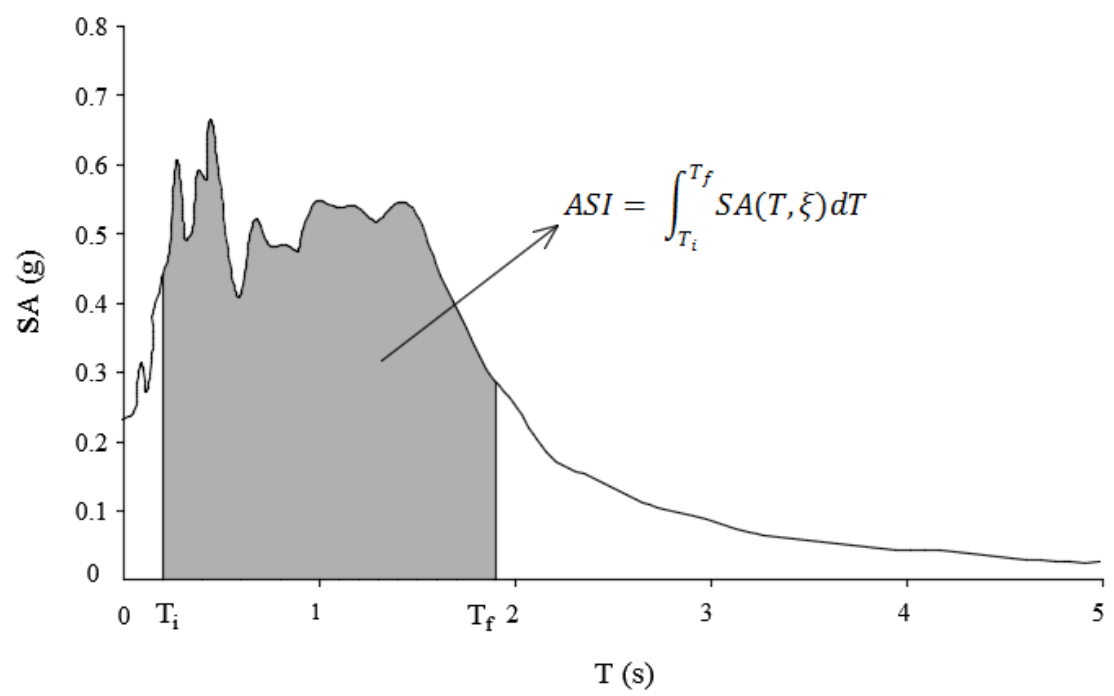

Figura 7. Intensidad de Aceleración Espectral ASI (Avsar, 2009)

Se pretende avanzar sobre el desarrollo de las curvas de fragilidad para dos clases de puentes identificadas como de "Vigas de Hormigon Simplemente Apoyado y de Tramos Multiples" y "Vigas Cajón de Hormigón Continua de Tramos Múltiples", según el estudio citado en la introducción (Saracho et al., 2016). Los análisis modales realizados en puentes típicos de estas dos clases ubicados en la provincia de Mendoza dieron como resultado periodos fundamentales de $0.9 \mathrm{~s}$ y $1.25 \mathrm{~s}$, respectivamente. Por otro lado, según prescripciones de ASCE/SEI 7-10 (2010), el rango de periodos a considerar para realizar el escalado de acelerogramas va desde $0.2 \mathrm{~T}$ a $1.5 \mathrm{~T}$, donde $\mathrm{T}$ es el periodo del primer modo de vibración de la estructura. Tal como se señaló, el límite superior de 1.5T toma en consideración el aumento del periodo por acción inelástica, mientras que el umbral inferior $(0.2 \mathrm{~T})$ trata de capturar los efectos de los modos superiores. Para el cálculo de $\mathrm{T}_{\mathrm{i}}$, ecuación (2), se empleará el periodo citado de menor valor: $0.9 \mathrm{~s}$, en tanto que para $\mathrm{T}_{\mathrm{f}}$, ecuación (3), el mayor: $1.25 \mathrm{~s}$.

$T_{i}=0.2 * 0.9 s=0.18 s$

$T_{f}=1.5 * 1.25 s=1.87 \mathrm{~s}$

Siguiendo a Avsar (2009), de acuerdo a Dhakal et al. (2006), usando un gran número de registros seguramente se incrementará notablemente la cantidad de análisis a ejecutar antes de llegar a alguna conclusión importante y, asimismo, no necesariamente se logrará enriquecer el resultado final. Otro problema aparejado al hecho de utilizar numerosos registros sin haber pasado por algún criterio racional de selección, lo constituye la muy probable desigual distribución de las medidas de intensidad sísmica (PGA). Con ello, los puntos para la obtención de las curvas de fragilidad procedentes de los resultados de los análisis estructurales pueden llegar a acumularse para ciertas medidas de intensidad sísmica (PGA), lo cual afectará la confiabilidad de las curvas de fragilidad en un sentido negativo. Con esta premisa en mente y asimismo por consideración de la clase de sitio, zonas de peligrosidad sísmica y niveles de amenaza sísmica, en el presente trabajo se arribará a distintas series de registros, surgidas de entre los 274 obtenidos en principio.

En virtud de la correlación existente entre el daño sísmico provocado en puentes y la magnitud ASI, una primera consigna para la selección de los registros sería la de descartar aquellos con más pequeños niveles de ASI para valores de PGA del mismo orden. Además de esto, el criterio que primó fue el hecho de tener una cantidad relativamente uniforme de registros en los distintos rangos de PGA y asimismo, contar con cierto número de sismos de tipo impulsivo, o de fuente cercana. Esto último surge de las 
recomendaciones efectuadas en NEHRP Consultants Joint Venture (2011) para el diseño de edificaciones en cercanía de fallas activas, como las existentes en la región de estudio. Todo lo señalado se dirimió por inspección visual de los registros volcados en un gráfico PGA versus ASI, tal como se hizo en Avsar (2009). Según se adelantó, esta operación se realizará discriminando tanto la clase de sitio, zonas de peligrosidad sísmica, como así también los dos niveles de amenaza sísmica involucrados.

\section{RESULTADOS Y DISCUSIÓN}

En primer lugar, para aclarar más el proceso, se mostrará uno de los resultados obtenidos en oportunidad de la búsqueda de registros. En figura 8 se ofrece un gráfico en el que están representados los espectros escalados de cada uno de los 10 registros obtenidos para un espectro objetivo que corresponde a la zona sísmica 4 -según INPRES CIRSOC 103 (2018)-, clase de sitio SD -INPRES CIRSOC 103 (2019)y nivel de amenaza sísmica de 2500 años de recurrencia.

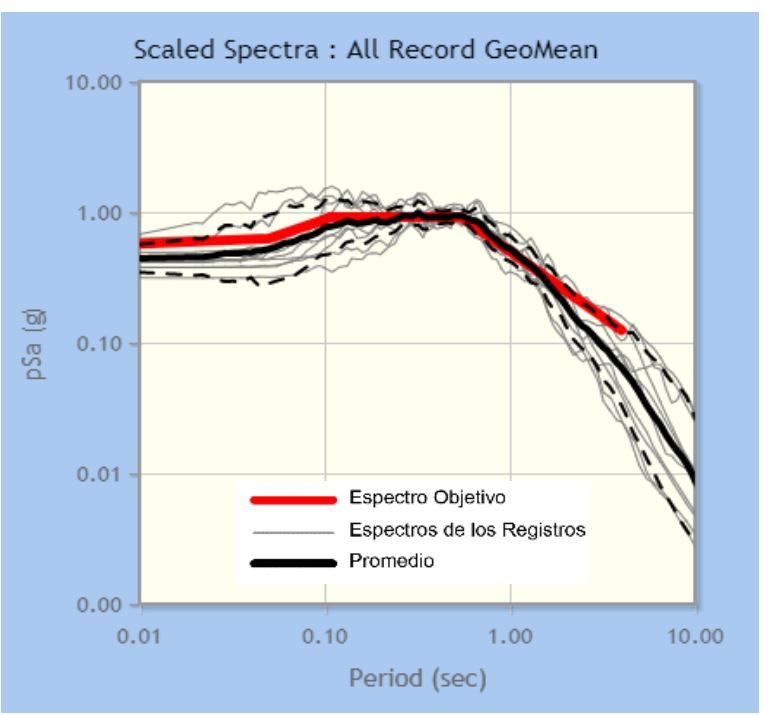

Figura 8. Espectros elásticos de los registros obtenidos para zona sísmica 4, clase de sitio SD y nivel de amenaza sísmica de 2500 años de recurrencia

Puede observarse el buen grado de aproximación del promedio de la serie respecto del espectro objetivo en el rango de periodos de significancia estructural.

A continuación, en figura 9, se presentan las historias de aceleración y velocidad de una de las componentes horizontales de uno de estos registros, compatible con el espectro objetivo ya referido, que corresponde al sismo de Gazli, USSR de 1976, registrado en la estación Karakyr. Este registro se representa escalado por su correspondiente factor, 0.844 , con una aceleración máxima de $0.73 \mathrm{~g}$. 


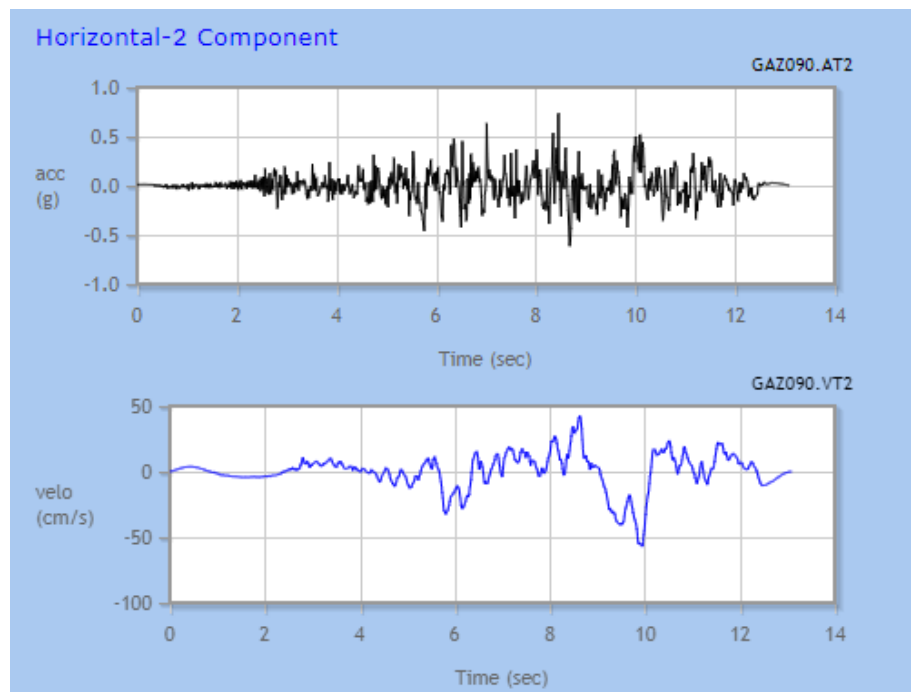

Figura 9. Componente horizontal del sismo de Gazli, USSR. PGA: $0.73 \mathrm{~g}$

En figura 10 se halla representado el espectro de respuesta del mencionado sismo. Obsérvese el buen grado de ajuste respecto del espectro objetivo.

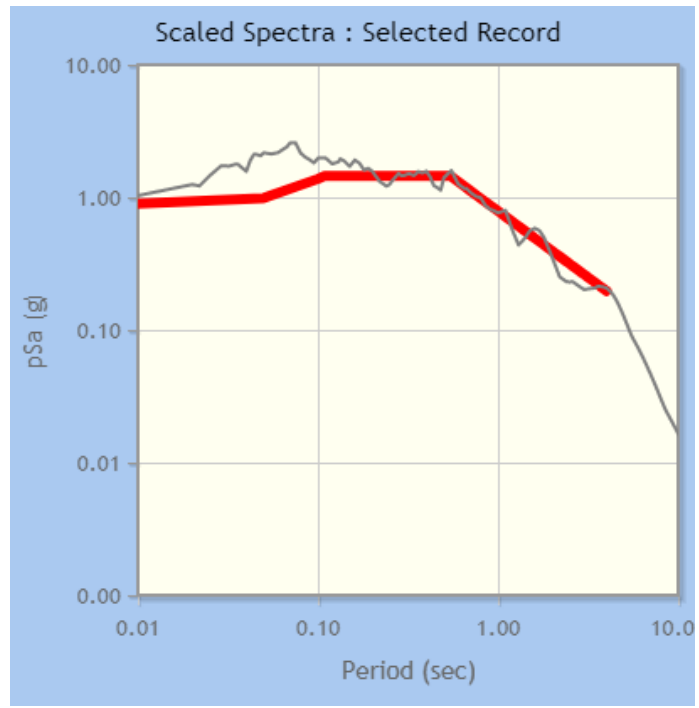

Figura 10. Espectro elástico del registro del sismo de Gazli, USSR

Para apreciar la diferencia, seguidamente se presenta en figura 11 un registro de tipo impulsivo. Se trata de las historias de aceleración y velocidad de una de las componentes horizontales del sismo de Parkfield, California, de 2004, registrado en la estación de Parkfield - Cholame, también compatible con el espectro objetivo anteriormente citado. Asimismo, este registro se representa afectado por su correspondiente factor de escala, 1.502, con una aceleración máxima de $0.661 \mathrm{~g}$. 


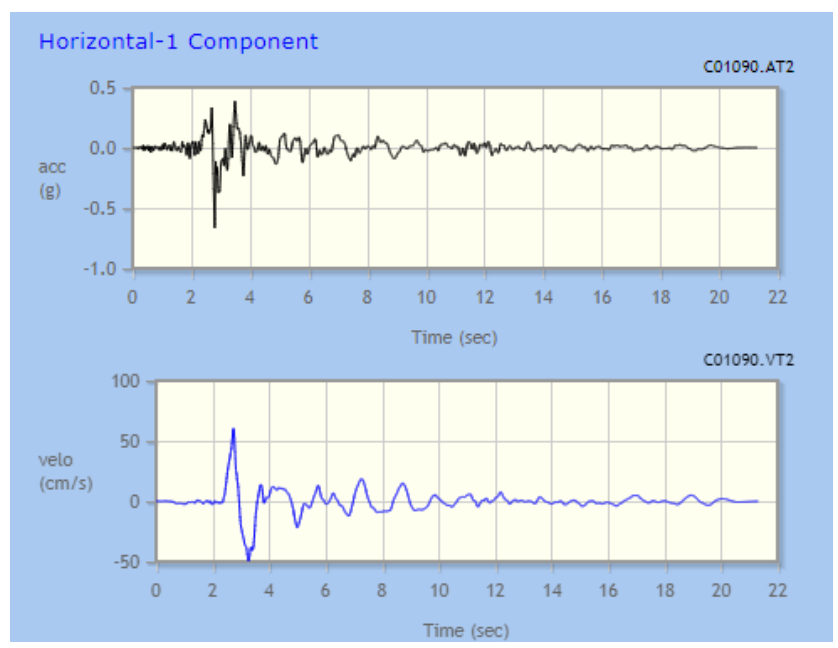

Figura 11. Componente horizontal del sismo de Parkfield. PGA: $0.661 \mathrm{~g}$

Ídem al caso anterior, en figura 12 se ofrece el espectro de respuesta de este registro sísmico, verificándose también el buen grado de ajuste.

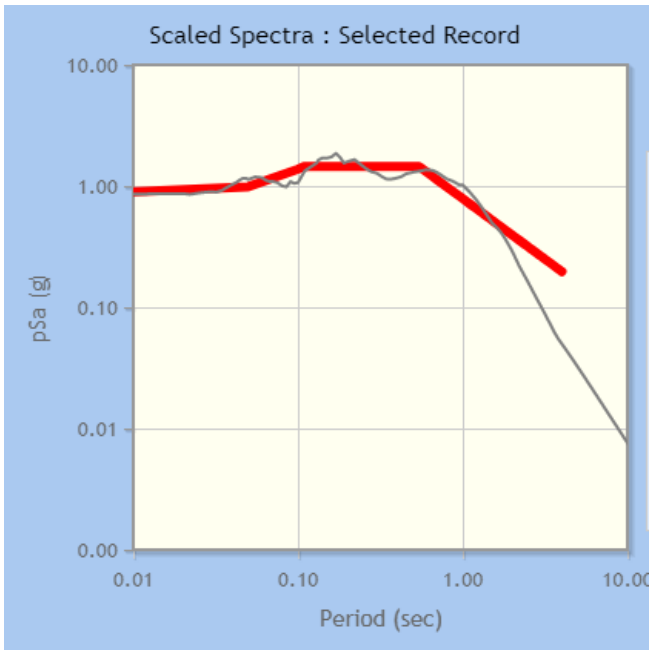

Figura 12. Espectro elástico del registro del sismo de Parkfield

En figura 13 se muestra el histograma de frecuencias de las aceleraciones máximas del terreno de los 274 sismos encontrados. Puede observarse la concentración hacia la izquierda, con énfasis en las aceleraciones menores que $0.5 \mathrm{~g}$, lo cual se debe obviamente a que para mayores valores de la aceleración máxima del terreno, los registros son cada vez más escasos. 


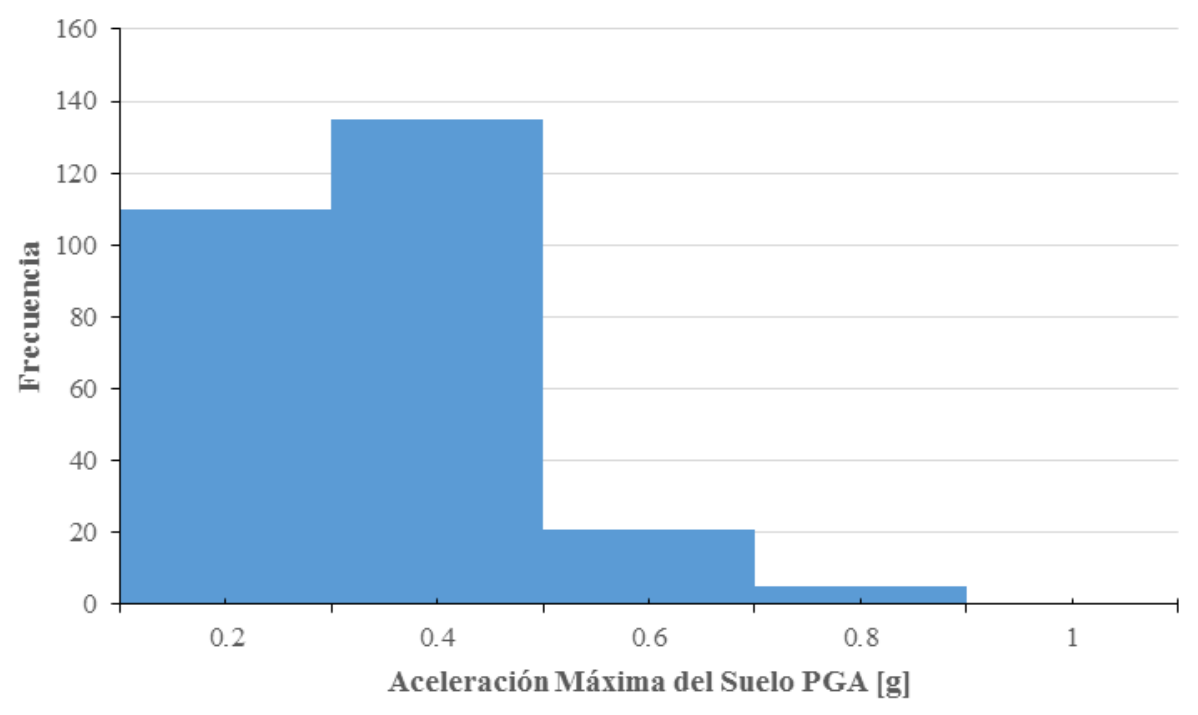

Figura 13. Histograma de frecuencias de PGA para los 274 sismos encontrados

A continuación, se presentan tanto los diagramas de distribución ASI versus PGA de los registros discriminados por clase de sitio, peligrosidad sísmica y nivel de amenaza sísmica, así como las tablas con algunos parámetros importantes de los sismos seleccionados.

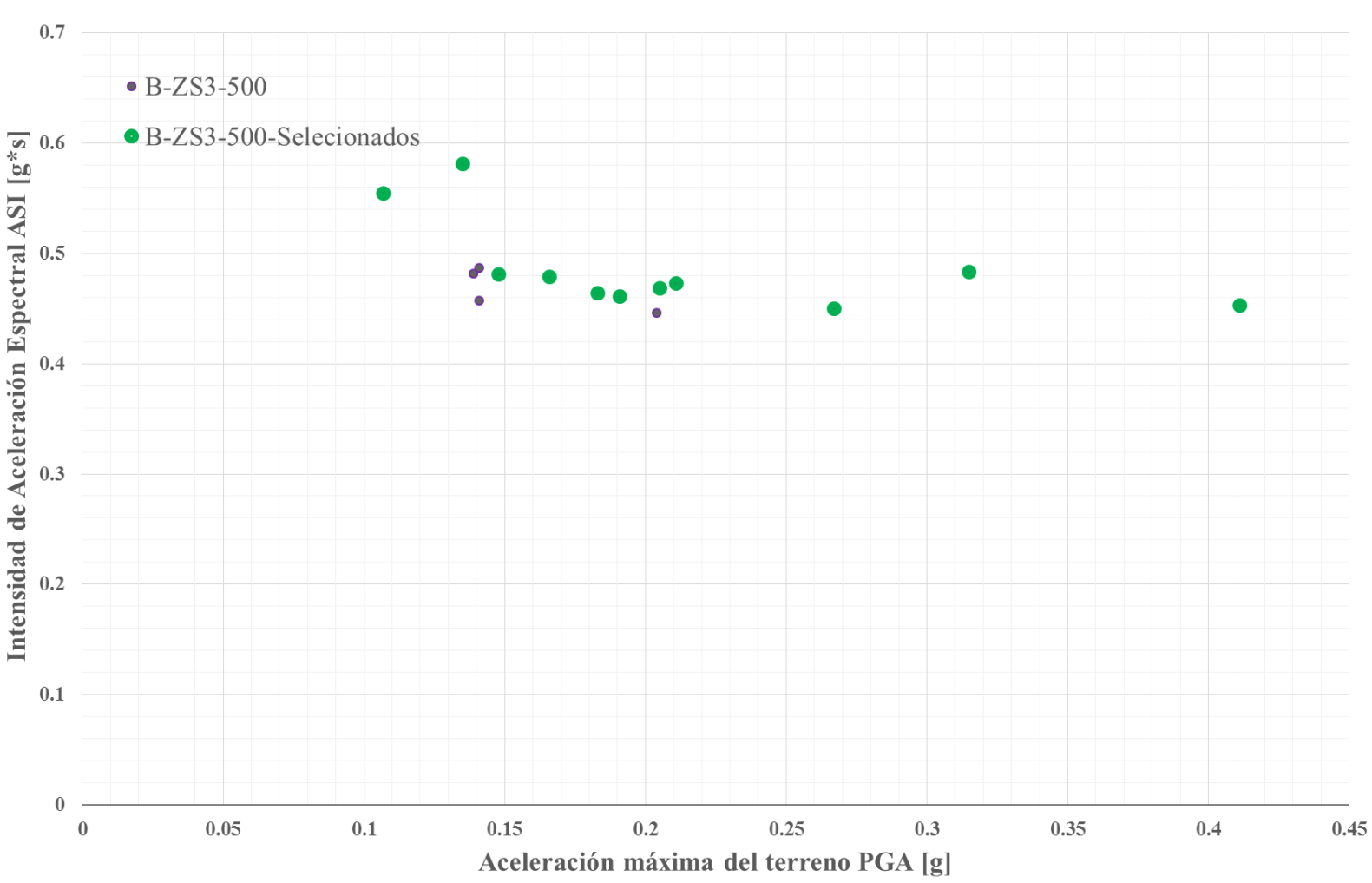

Figura 14. Distribución ASI versus PGA para los sismos de clase de sitio B, zona sísmica 3 y nivel de amenaza sísmica de 500 años 
Tabla 4. Algunos parámetros importantes de los sismos seleccionados correspondientes a clase de sitio B, zona sísmica 3 y nivel de amenaza sísmica de 500 años

\begin{tabular}{|c|c|c|c|c|c|c|c|c|c|c|}
\hline $\begin{array}{l}\text { Numero } \\
\text { de } \\
\text { secuenci } \\
\text { a del } \\
\text { registro }\end{array}$ & $\begin{array}{c}\text { Factor } \\
\text { de } \\
\text { escala }\end{array}$ & $\begin{array}{c}\text { Period } \\
\text { o del } \\
\text { Pulso - } \\
\text { Tp (s) }\end{array}$ & $\begin{array}{l}\text { Duraci } \\
\text { ón } \\
5-95 \% \\
\text { (s) }\end{array}$ & $\begin{array}{c}\text { Intensi } \\
\text { dad de } \\
\text { Arias } \\
(\mathrm{m} / \mathrm{s})\end{array}$ & Nombre del sismo & Año & $\begin{array}{l}\text { Magni } \\
\text { tud }\end{array}$ & $\begin{array}{l}\text { Mecanism } \\
\text { o de falla }\end{array}$ & $\begin{array}{c}\text { Distan } \\
\text { cia } \\
\text { desde } \\
\text { la falla } \\
(\mathrm{km})\end{array}$ & $\begin{array}{l}\text { Vs30 } \\
(\mathrm{m} / \mathrm{s})\end{array}$ \\
\hline 80 & 1.3013 & - & 14.1 & 0.3 & "San Fernando" & 1971 & 6.61 & & 21.5 & 969.07 \\
\hline 804 & 1.8165 & - & 12.1 & 0.1 & "Loma Prieta" & 1989 & 6.93 & Oblique & 63.03 & 1020.62 \\
\hline 1011 & 1.2896 & - & 8.7 & 0.2 & "Northridge-01" & 1994 & 6.69 & $\begin{array}{l}\text { Reverse } \\
\text { Reverse }\end{array}$ & 15.11 & 1222.52 \\
\hline 1256 & 1.8355 & - & 24.4 & 0.1 & "Chi-Chi_Taiwan" & 1999 & 7.62 & Oblique & 53.3 & 789.18 \\
\hline 3925 & 2.2265 & - & 19.6 & 0.3 & "Tottori_Japan" & 2000 & 6.61 & strike slip & 15.23 & 940.2 \\
\hline 5618 & 0.6332 & - & 22.6 & 1.4 & "Iwate_Japan" & 2008 & 6.9 & $\begin{array}{l}\text { Reverse } \\
\text { Reverse }\end{array}$ & 16.26 & 825.83 \\
\hline 789 & 1.4417 & - & 10.6 & 0.1 & "Loma Prieta" & 1989 & 6.93 & $\begin{array}{l}\text { Oblique } \\
\text { Reverse }\end{array}$ & 83.37 & 1315.92 \\
\hline 795 & 2.1511 & - & 11.9 & 0.1 & "Loma Prieta" & 1989 & 6.93 & Oblique & 75.96 & 1249.86 \\
\hline 879 & 0.3993 & 5.124 & 13.8 & 7 & "Landers" & 1992 & 7.28 & strike slip & 2.19 & 1369 \\
\hline 1161 & 0.8081 & 5.992 & 8.2 & 0.5 & "Kocaeli_Turkey" & 1999 & 7.51 & strike slip & 7.57 & 792 \\
\hline 1165 & 0.6413 & 5.369 & 15.1 & 0.8 & "Kocaeli_Turkey" & 1999 & 7.51 & strike slip & 3.62 & 811 \\
\hline
\end{tabular}

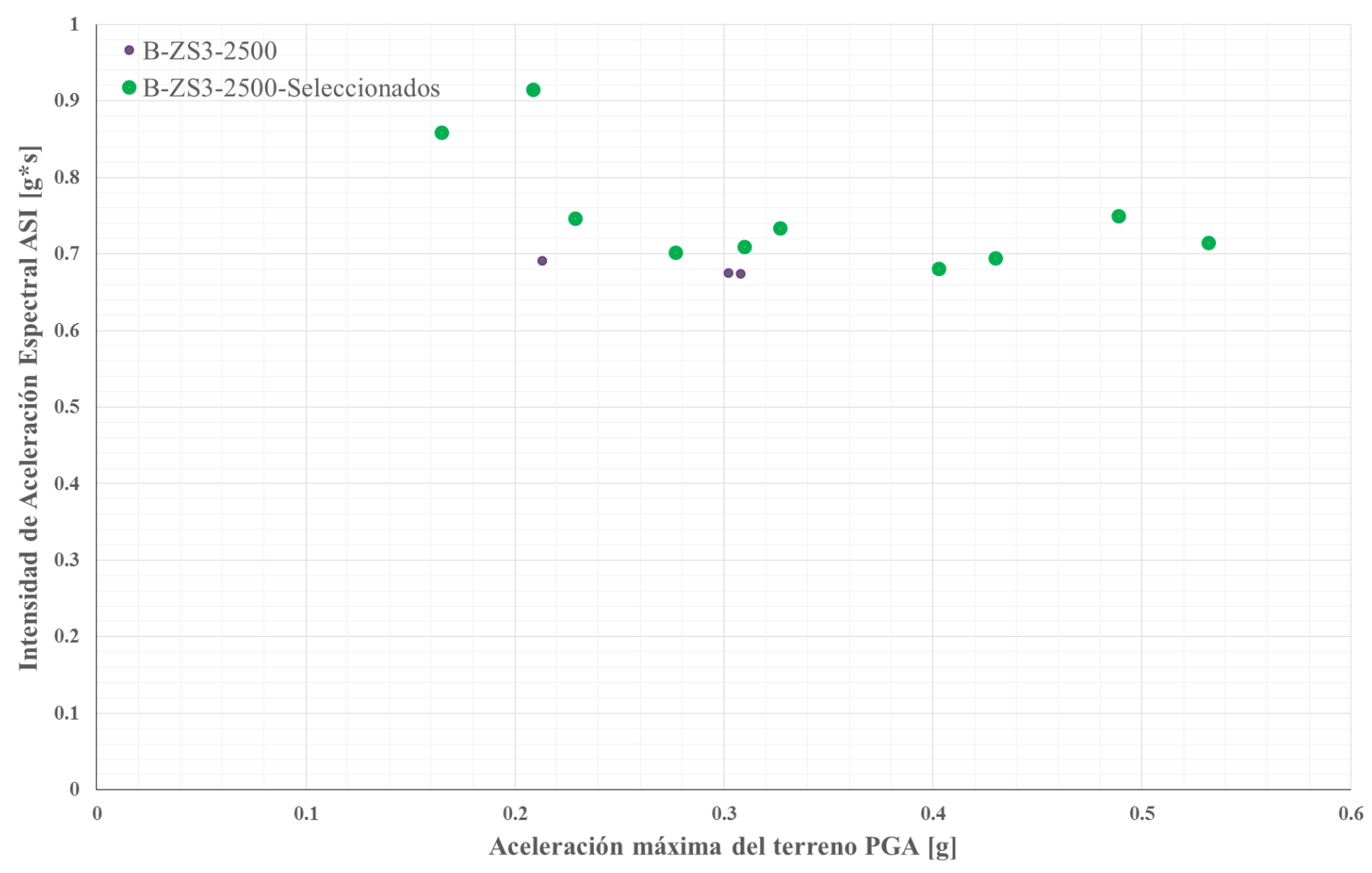

Figura 15. Distribución ASI versus PGA para los sismos de clase de sitio B, zona sísmica 3 y nivel de amenaza sísmica de 2500 años 
Tabla 5. Algunos parámetros importantes de los sismos seleccionados correspondientes a clase de sitio B, zona sísmica 3 y nivel de amenaza sísmica de 2500 años

\begin{tabular}{|c|c|c|c|c|c|c|c|c|c|c|}
\hline $\begin{array}{l}\text { Numero } \\
\text { de } \\
\text { secuenci } \\
\text { a del } \\
\text { registro }\end{array}$ & $\begin{array}{l}\text { Factor } \\
\text { de } \\
\text { escala }\end{array}$ & $\begin{array}{c}\text { Period } \\
\text { o del } \\
\text { Pulso - } \\
\text { Tp (s) }\end{array}$ & $\begin{array}{l}\text { Duraci } \\
\text { ón } \\
5-95 \% \\
\text { (s) }\end{array}$ & $\begin{array}{c}\text { Intensi } \\
\text { dad de } \\
\text { Arias } \\
(\mathrm{m} / \mathrm{s})\end{array}$ & Nombre del sismo & Año & $\begin{array}{l}\text { Mag } \\
\text { nitud }\end{array}$ & $\begin{array}{c}\text { Mecanismo } \\
\text { de falla }\end{array}$ & $\begin{array}{c}\text { Distan } \\
\text { cia } \\
\text { desde } \\
\text { la falla } \\
(\mathrm{km})\end{array}$ & $\begin{array}{l}\text { Vs30 } \\
(\mathrm{m} / \mathrm{s})\end{array}$ \\
\hline 80 & 1.9683 & - & 14.1 & 0.3 & "San Fernando" & 1971 & 6.61 & $\begin{array}{l}\text { Reverse } \\
\text { Reverse }\end{array}$ & 21.5 & 969.07 \\
\hline 789 & 2.2316 & - & 10.6 & 0.1 & "Loma Prieta" & 1989 & 6.93 & Oblique & 83.37 & 1315.92 \\
\hline 1011 & 1.9506 & - & 8.7 & 0.2 & "Northridge-01" & 1994 & 6.69 & Reverse & 15.11 & 1222.52 \\
\hline 4083 & 1.751 & - & 8.8 & 0.2 & "Parkfield-02_CA" & 2004 & 6 & strike slip & 4.66 & 906.96 \\
\hline 5618 & 0.9578 & - & 22.6 & 1.4 & "Iwate_Japan" & 2008 & 6.9 & Reverse & 16.26 & 825.83 \\
\hline 8165 & 0.5167 & - & - & - & "Duzce_Turkey" & 1999 & 7.14 & strike slip & 4.21 & 760 \\
\hline 879 & 0.6193 & 5.124 & 13.8 & 7 & "Landers" & 1992 & 7.28 & strike slip & 2.19 & 1369 \\
\hline 1161 & 1.2533 & 5.992 & 8.2 & 0.5 & "Kocaeli_Turkey" & 1999 & 7.51 & strike slip & 7.57 & 792 \\
\hline 1165 & 0.9946 & 5.369 & 15.1 & 0.8 & "Kocaeli_Turkey" & 1999 & 7.51 & $\begin{array}{l}\text { strike slip } \\
\text { Reverse }\end{array}$ & 3.62 & 811 \\
\hline 3548 & 0.4712 & 1.568 & 4.3 & 1.9 & "Loma Prieta" & 1989 & 6.93 & Oblique & 3.22 & 1070.34 \\
\hline
\end{tabular}

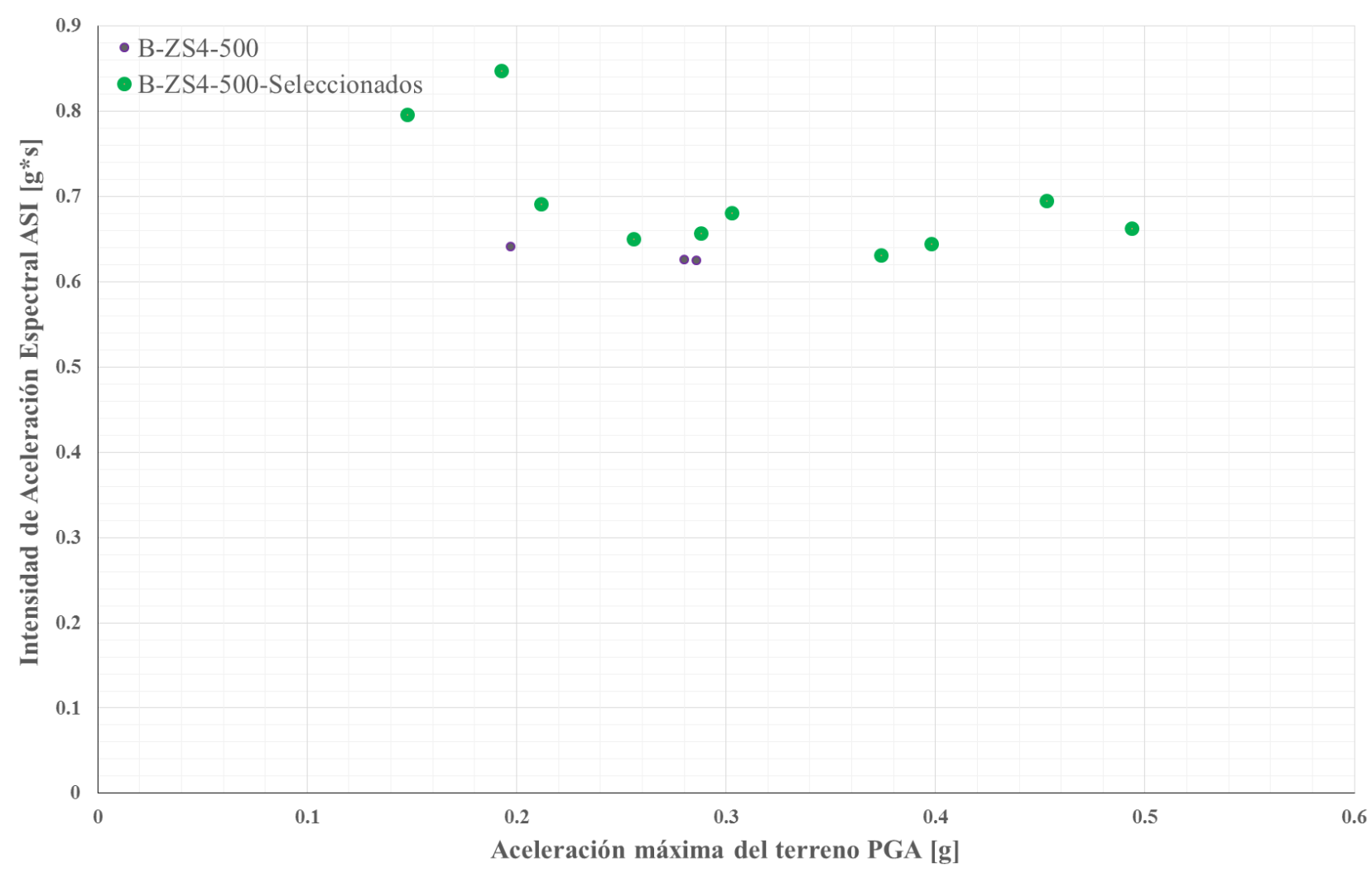

Figura 16. Distribución ASI versus PGA para los sismos de clase de sitio B, zona sísmica 4 y nivel de amenaza sísmica de 500 años 
Tabla 6. Algunos parámetros importantes de los sismos seleccionados correspondientes a clase de sitio B, zona sísmica 4 y nivel de amenaza sísmica de 500 años

\begin{tabular}{|c|c|c|c|c|c|c|c|c|c|c|}
\hline $\begin{array}{l}\text { Numer } \\
\text { o de } \\
\text { secuen } \\
\text { cia del } \\
\text { registr } \\
\text { o } \\
\end{array}$ & $\begin{array}{l}\text { Factor } \\
\text { de } \\
\text { escala }\end{array}$ & $\begin{array}{l}\text { Period } \\
\text { o del } \\
\text { Pulso - } \\
\text { Tp (s) }\end{array}$ & $\begin{array}{l}\text { Duración } \\
5-95 \% \\
\text { (s) }\end{array}$ & $\begin{array}{c}\text { Intensid } \\
\text { ad de } \\
\text { Arias } \\
(\mathrm{m} / \mathrm{s})\end{array}$ & Nombre del sismo & Año & $\begin{array}{l}\text { Mag } \\
\text { nitud }\end{array}$ & $\begin{array}{l}\text { Mecanism } \\
\text { o de falla }\end{array}$ & $\begin{array}{c}\text { Distan } \\
\text { cia } \\
\text { desde } \\
\text { la falla } \\
(\mathrm{km}) \\
\end{array}$ & $\begin{array}{l}\text { Vs30 } \\
(\mathrm{m} / \mathrm{s})\end{array}$ \\
\hline 80 & 1.8245 & - & 14.1 & 0.3 & "San Fernando" & 1971 & 6.61 & & 21.5 & 969.07 \\
\hline 789 & 2.0685 & - & 10.6 & 0.1 & "Loma Prieta" & 1989 & 6.93 & Oblique & 83.37 & 1315.92 \\
\hline 1011 & 1.808 & - & 8.7 & 0.2 & $\begin{array}{l}\text { "Northr } \\
\text { "Parkfie }\end{array}$ & 1994 & 6.69 & Reverse & 15.11 & 1222.52 \\
\hline 4083 & 1.623 & - & 8.8 & 0.2 & CA" & 2004 & 6 & strike slip & 4.66 & 906.96 \\
\hline 5618 & 0.8878 & - & 22.6 & 1.4 & "Iwate_Japan" & 2008 & 6.9 & Reverse & 16.26 & 825.83 \\
\hline 8165 & 0.4789 & - & - & - & "Duzce_Turkey" & 1999 & 7.14 & strike slip & 4.21 & 760 \\
\hline 879 & 0.574 & 5.124 & 13.8 & 7 & "Landers" & 1992 & 7.28 & strike slip & 2.19 & 1369 \\
\hline 1161 & 1.1617 & 5.992 & 8.2 & 0.5 & "Kocaeli_Turkey" & 1999 & 7.51 & strike slip & 7.57 & 792 \\
\hline 1165 & 0.9219 & 5.369 & 15.1 & 0.8 & "Kocaeli_Turkey" & 1999 & 7.51 & $\begin{array}{l}\text { strike slip } \\
\text { Reverse }\end{array}$ & 3.62 & 811 \\
\hline 3548 & 0.4368 & 1.568 & 4.3 & 1.9 & "Loma Prieta" & 1989 & 6.93 & Oblique & 3.22 & 1070.34 \\
\hline
\end{tabular}

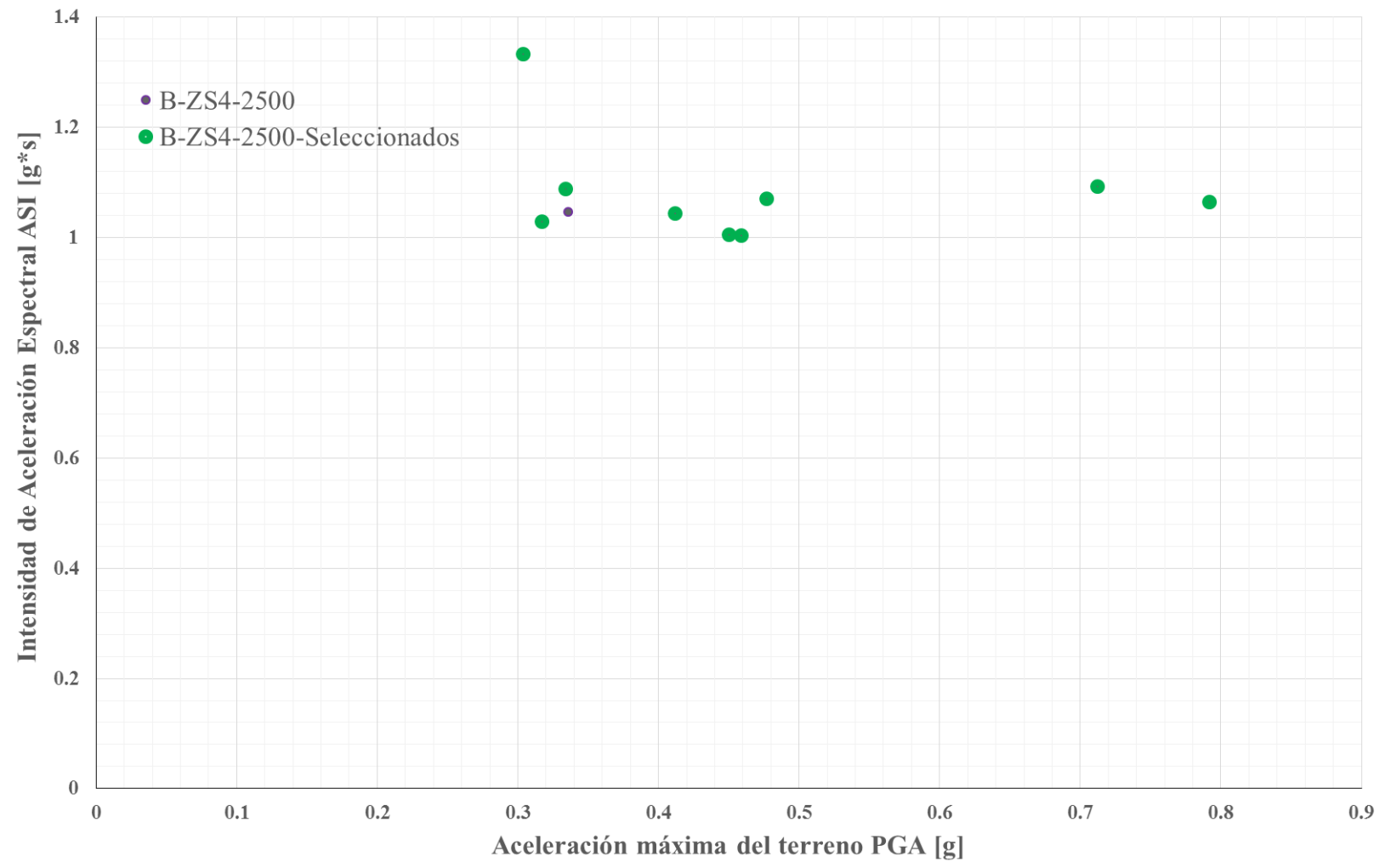

Figura 17. Distribución ASI versus PGA para los sismos de clase de sitio B, zona sísmica 4 y nivel de amenaza sísmica de 2500 años 
Tabla 7. Algunos parámetros importantes de los sismos seleccionados correspondientes a clase de sitio B, zona sísmica 4 y nivel de amenaza sísmica de 2500 años

\begin{tabular}{|c|c|c|c|c|c|c|c|c|c|c|}
\hline $\begin{array}{l}\text { Numero } \\
\text { de } \\
\text { secuenci } \\
\text { a del } \\
\text { registro }\end{array}$ & $\begin{array}{l}\text { Factor } \\
\text { de } \\
\text { escala }\end{array}$ & $\begin{array}{c}\text { Periodo } \\
\text { del } \\
\text { Pulso - } \\
\text { Tp (s) }\end{array}$ & $\begin{array}{l}\text { Duraci } \\
\text { ón } \\
5-95 \% \\
\text { (s) }\end{array}$ & $\begin{array}{c}\text { Intensid } \\
\text { ad de } \\
\text { Arias } \\
(\mathrm{m} / \mathrm{s})\end{array}$ & $\begin{array}{l}\text { Nombre del } \\
\text { sismo }\end{array}$ & Año & $\begin{array}{l}\text { Magn } \\
\text { itud }\end{array}$ & $\begin{array}{c}\text { Mecanism } \\
\text { o de falla }\end{array}$ & $\begin{array}{c}\text { Distanci } \\
\text { a desde } \\
\text { la falla } \\
(\mathrm{km})\end{array}$ & $\begin{array}{l}\text { Vs30 } \\
(\mathrm{m} / \mathrm{s})\end{array}$ \\
\hline & & & & & & & & Reverse & & 1428.1 \\
\hline 765 & 0.6225 & - & 6.5 & 1.7 & $\begin{array}{l}\text { "Loma Prieta" } \\
\text { "Northridge- }\end{array}$ & 1989 & 6.93 & Oblique & 8.84 & 4 \\
\hline 1091 & 1.4077 & - & 8.3 & 0.4 & $\begin{array}{l}\text { 01" } \\
\text { "Tottori }\end{array}$ & 1994 & 6.69 & Reverse & 23.1 & 996.43 \\
\hline 3954 & 1.337 & - & 12.8 & 0.5 & Japan" & 2000 & 6.61 & strike slip & 15.58 & 967.27 \\
\hline 5618 & 0.9578 & - & 22.6 & 1.4 & $\begin{array}{l}\text { "Iwate_Japan" } \\
\text { "Duzce }\end{array}$ & 2008 & 6.9 & Reverse & 16.26 & 825.83 \\
\hline 8165 & 0.5167 & - & - & - & Turkey" & 1999 & 7.14 & strike slip & 4.21 & 760 \\
\hline 879 & 0.6193 & 5.124 & 13.8 & 7 & $\begin{array}{l}\text { "Landers" } \\
\text { "Kocaeli_ }\end{array}$ & 1992 & 7.28 & strike slip & 2.19 & 1369 \\
\hline 1161 & 1.2533 & 5.992 & 8.2 & 0.5 & $\begin{array}{l}\text { Turkey" } \\
\text { "Kocaeli_ }\end{array}$ & 1999 & 7.51 & strike slip & 7.57 & 792 \\
\hline 1165 & 0.9946 & 5.369 & 15.1 & 0.8 & Turkey" & 1999 & 7.51 & $\begin{array}{l}\text { strike slip } \\
\text { Reverse }\end{array}$ & 3.62 & $\begin{array}{r}811 \\
1070.3\end{array}$ \\
\hline 3548 & 0.4712 & 1.568 & 4.3 & 1.9 & "Loma Prieta" & 1989 & 6.93 & Oblique & 3.22 & 4 \\
\hline
\end{tabular}

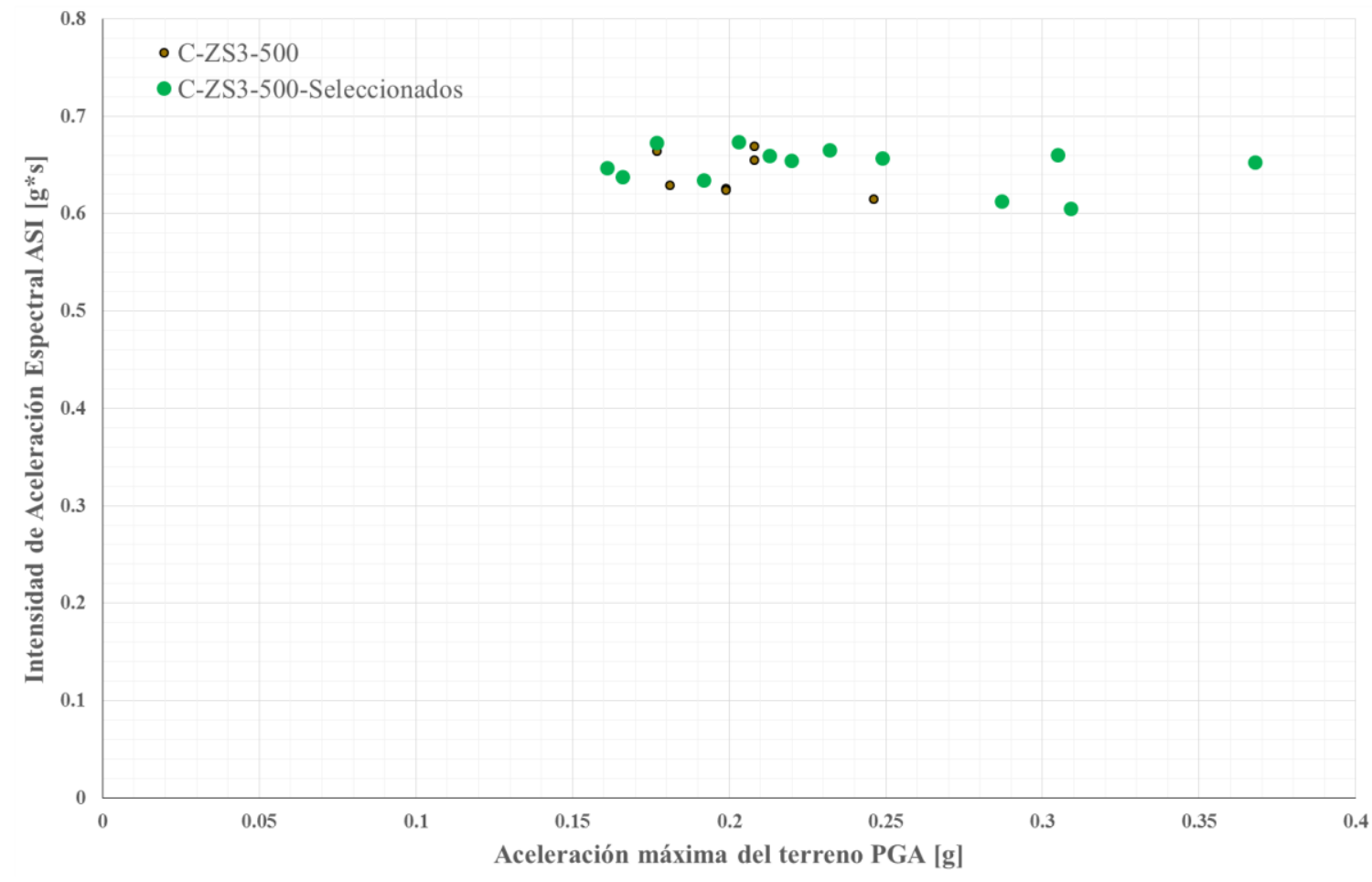

Figura 18. Distribución ASI versus PGA para los sismos de clase de sitio C, zona sísmica 3 y nivel de amenaza sísmica de 500 años 
Tabla 8. Algunos parámetros importantes de los sismos seleccionados correspondientes a clase de sitio C, zona sísmica 3 y nivel de amenaza sísmica de 500 años

\begin{tabular}{|c|c|c|c|c|c|c|c|c|c|c|}
\hline $\begin{array}{l}\text { Numero } \\
\text { de } \\
\text { secuencia } \\
\text { del } \\
\text { registro }\end{array}$ & $\begin{array}{l}\text { Factor } \\
\text { de } \\
\text { escala }\end{array}$ & $\begin{array}{l}\text { Periodo } \\
\text { del } \\
\text { Pulso - } \\
\text { Tp (s) }\end{array}$ & $\begin{array}{l}\text { Duración } \\
5-95 \% \\
\text { (s) }\end{array}$ & $\begin{array}{c}\text { Intensidad } \\
\text { de Arias } \\
(\mathrm{m} / \mathrm{s})\end{array}$ & Nombre del sismo & Año & Magnitud & $\begin{array}{l}\text { Mecanismo de } \\
\text { falla }\end{array}$ & $\begin{array}{c}\text { Distancia } \\
\text { desde la } \\
\text { falla } \\
(\mathrm{km})\end{array}$ & $\begin{array}{l}\text { Vs30 } \\
(\mathrm{m} / \mathrm{s})\end{array}$ \\
\hline 164 & 0.9826 & - & 36.4 & 1.3 & "Imperial Valley-06" & 1979 & 6.53 & strike slip & 15.19 & 471.53 \\
\hline 265 & 0.5692 & - & 8.2 & 2 & "Victoria_Mexico" & 1980 & 6.33 & strike slip & 13.8 & 471.53 \\
\hline 357 & 2.0446 & - & 12.2 & 0.1 & "Coalinga-01" & 1983 & 6.36 & Reverse & 32.81 & 565.08 \\
\hline 548 & 1.1885 & - & 16.6 & 0.4 & $\begin{array}{l}\text { "Chalfant Valley-02" } \\
\text { "Taiwan }\end{array}$ & 1986 & 6.19 & strike slip & 21.55 & 370.94 \\
\hline 572 & 1.3473 & - & 12.4 & 0.4 & SMART1(45)" & 1986 & 7.3 & Reverse & 51.35 & 671.52 \\
\hline 735 & 1.4069 & - & 16 & 0.3 & "Loma Prieta" & 1989 & 6.93 & Reverse Oblique & 41.68 & 415.27 \\
\hline 802 & 0.5927 & 4.571 & 9.4 & 1.5 & "Loma Prieta" & 1989 & 6.93 & Reverse Oblique & 7.58 & 380.89 \\
\hline 1193 & 0.7207 & 6.65 & 27 & 1.8 & "Chi-Chi_Taiwan" & 1999 & 7.62 & Reverse Oblique & 9.62 & 427.73 \\
\hline 1476 & 1.1662 & 5.285 & 22.3 & 0.8 & "Chi-Chi_Taiwan" & 1999 & 7.62 & Reverse Oblique & 28.04 & 406.53 \\
\hline 1511 & 0.4973 & 4.732 & 29.5 & 3.7 & "Chi-Chi_Taiwan" & 1999 & 7.62 & Reverse Oblique & 2.74 & 614.98 \\
\hline 1528 & 0.7943 & 10.318 & 19.2 & 1 & "Chi-Chi_Taiwan" & 1999 & 7.62 & Reverse Oblique & 2.11 & 389.41 \\
\hline 2734 & 0.4722 & 2.436 & 7.4 & 1.6 & "Chi-Chi_Taiwan-04" & 1999 & 6.2 & strike slip & 6.02 & 553.43 \\
\hline 4228 & 0.4791 & 1.799 & 12.2 & 2.2 & "Niigata_Japan" & 2004 & 6.63 & Reverse & 6.27 & 375 \\
\hline
\end{tabular}

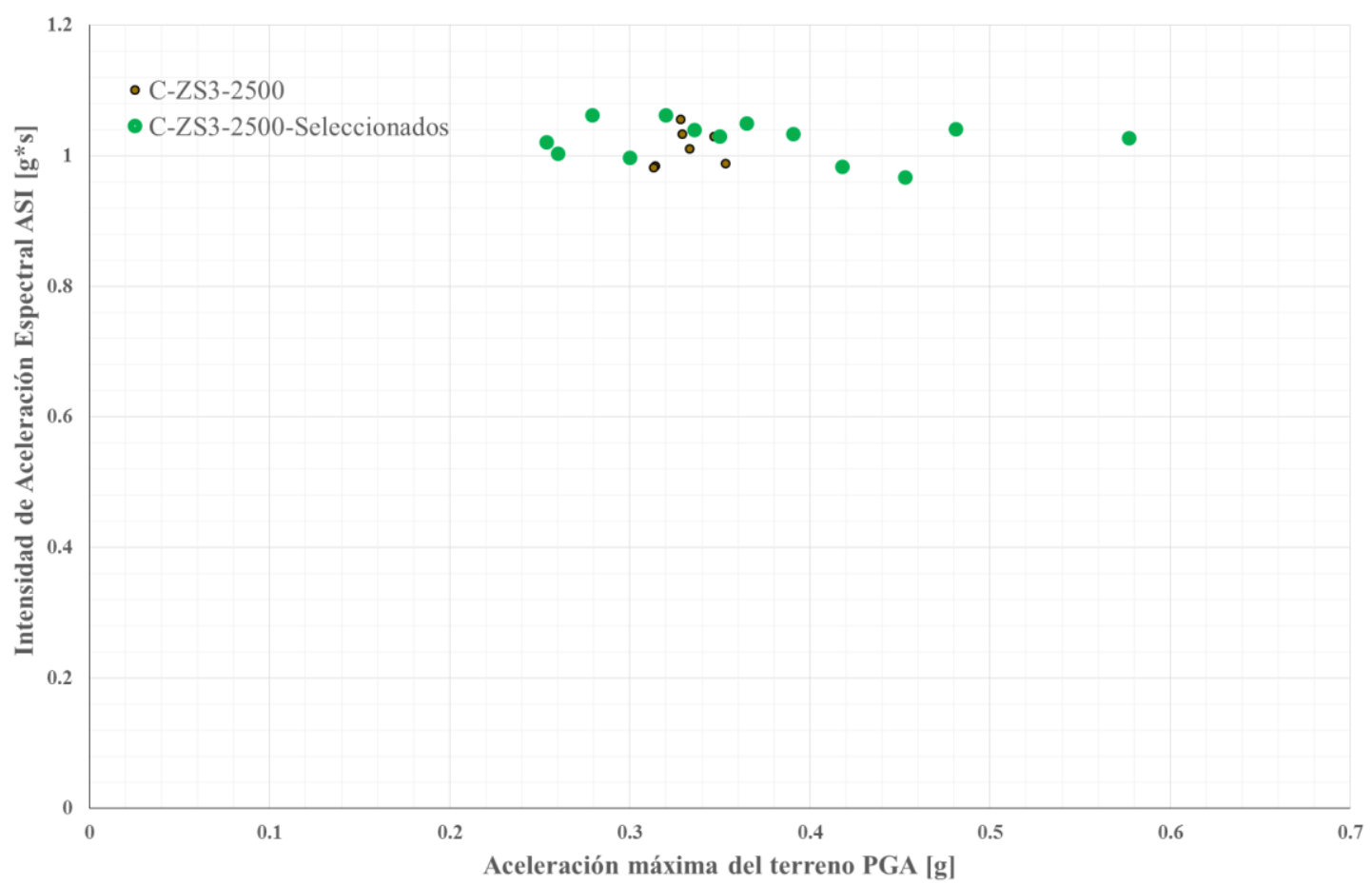

Figura 19. Distribución ASI versus PGA para los sismos de clase de sitio C, zona sísmica 3 y nivel de amenaza sísmica de 2500 años 
Tabla 9. Algunos parámetros importantes de los sismos seleccionados correspondientes a clase de sitio C, zona sísmica 3 y nivel de amenaza sísmica de 2500 años

\begin{tabular}{|c|c|c|c|c|c|c|c|c|c|c|}
\hline $\begin{array}{l}\text { Numero } \\
\text { de } \\
\text { secuenci } \\
\text { a del } \\
\text { registro }\end{array}$ & $\begin{array}{l}\text { Factor } \\
\text { de } \\
\text { escala }\end{array}$ & $\begin{array}{c}\text { Period } \\
\text { o del } \\
\text { Pulso - } \\
\text { Tp (s) }\end{array}$ & $\begin{array}{c}\text { Duración } \\
5-95 \% \\
\text { (s) }\end{array}$ & $\begin{array}{c}\text { Intensidad } \\
\text { de Arias } \\
(\mathrm{m} / \mathrm{s})\end{array}$ & $\begin{array}{l}\text { Nombre del } \\
\text { sismo }\end{array}$ & Año & Magnitud & $\begin{array}{l}\text { Mecanismo de } \\
\text { falla }\end{array}$ & $\begin{array}{l}\text { Distancia } \\
\text { desde la } \\
\text { falla }(\mathrm{km})\end{array}$ & $\mathrm{Vs} 30(\mathrm{~m} / \mathrm{s})$ \\
\hline 57 & 1.3041 & - & 16.8 & 1 & $\begin{array}{l}\text { "San Fernando" } \\
\text { "Imperial }\end{array}$ & 1971 & 6.61 & Reverse & 19.33 & 450.28 \\
\hline 164 & 1.5454 & - & 36.4 & 1.3 & $\begin{array}{l}\text { Valley-06" } \\
\text { "Victoria_ }\end{array}$ & 1979 & 6.53 & strike slip & 15.19 & 471.53 \\
\hline 265 & 0.8952 & - & 8.2 & 2 & $\begin{array}{l}\text { Mexico" } \\
\text { "Chalfant }\end{array}$ & 1980 & 6.33 & strike slip & 13.8 & 471.53 \\
\hline 548 & 1.8692 & - & 16.6 & 0.4 & $\begin{array}{l}\text { Valley-02" } \\
\text { "Taiwan }\end{array}$ & 1986 & 6.19 & strike slip & 21.55 & 370.94 \\
\hline 572 & 2.1189 & - & 12.4 & 0.4 & SMART1(45)" & 1986 & 7.3 & $\begin{array}{l}\text { Reverse } \\
\text { Reverse }\end{array}$ & 51.35 & 671.52 \\
\hline 802 & 0.935 & 4.571 & 9.4 & 1.5 & "Loma Prieta" & 1989 & 6.93 & Oblique & 7.58 & 380.89 \\
\hline 1086 & 0.4142 & 2.436 & 6.8 & 5 & $\begin{array}{l}\text { "Northridge-01" } \\
\text { "Chi-Chi_ }\end{array}$ & 1994 & 6.69 & $\begin{array}{l}\text { Reverse } \\
\text { Reverse }\end{array}$ & 1.74 & 440.54 \\
\hline 1193 & 1.1369 & 6.65 & 27 & 1.8 & $\begin{array}{l}\text { Taiwan" } \\
\text { "Chi-Chi__ }\end{array}$ & 1999 & 7.62 & $\begin{array}{l}\text { Oblique } \\
\text { Reverse }\end{array}$ & 9.62 & 427.73 \\
\hline 1476 & 1.8396 & 5.285 & 22.3 & 0.8 & $\begin{array}{l}\text { Taiwan" } \\
\text { "Chi-Chi_ }\end{array}$ & 1999 & 7.62 & $\begin{array}{l}\text { Oblique } \\
\text { Reverse }\end{array}$ & 28.04 & 406.53 \\
\hline 1511 & 0.7845 & 4.732 & 29.5 & 3.7 & $\begin{array}{l}\text { Taiwan" } \\
\text { "Chi-Chi_ }\end{array}$ & 1999 & 7.62 & $\begin{array}{l}\text { Oblique } \\
\text { Reverse }\end{array}$ & 2.74 & 614.98 \\
\hline 1528 & 1.2529 & 10.318 & 19.2 & 1 & $\begin{array}{l}\text { Taiwan" } \\
\text { "Chi-Chi__ }\end{array}$ & 1999 & 7.62 & Oblique & 2.11 & 389.41 \\
\hline 2734 & 0.7449 & 2.436 & 7.4 & 1.6 & $\begin{array}{l}\text { Taiwan-04" } \\
\text { "Niigata_ }\end{array}$ & 1999 & 6.2 & strike slip & 6.02 & 553.43 \\
\hline 4228 & 0.7558 & 1.799 & 12.2 & 2.2 & Japan" & 2004 & 6.63 & Reverse & 6.27 & 375 \\
\hline
\end{tabular}

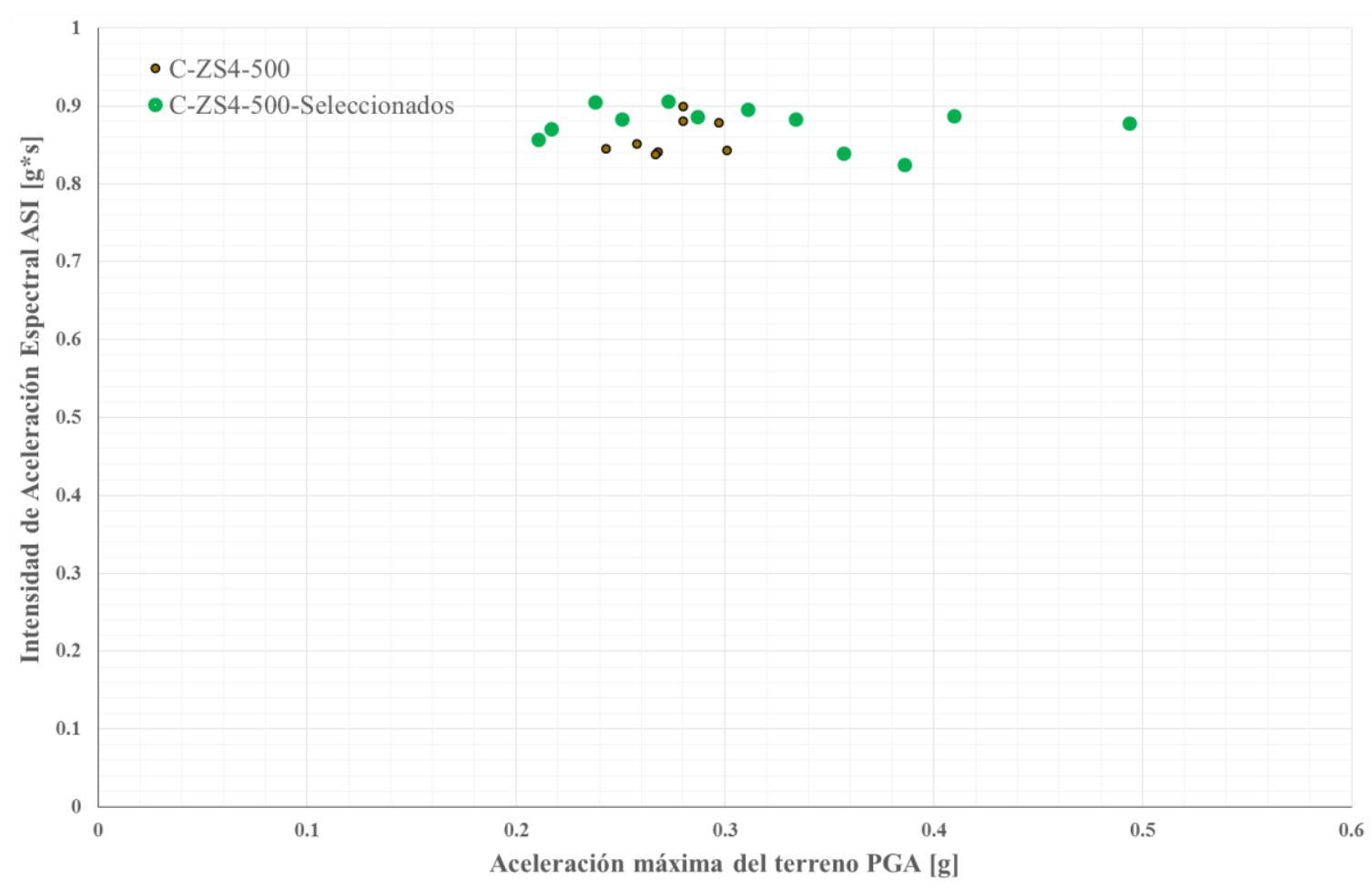

Figura 20. Distribución ASI versus PGA para los sismos de clase de sitio C, zona sísmica 4 y nivel de amenaza sísmica de 500 años 
Tabla 10. Algunos parámetros importantes de los sismos seleccionados correspondientes a clase de sitio C, zona sísmica 4 y nivel de amenaza sísmica de 500 años

\begin{tabular}{|c|c|c|c|c|c|c|c|c|c|c|}
\hline $\begin{array}{l}\text { Numero } \\
\text { de } \\
\text { secuencia } \\
\text { del } \\
\text { registro }\end{array}$ & $\begin{array}{l}\text { Factor } \\
\text { de } \\
\text { escala }\end{array}$ & $\begin{array}{c}\text { Periodo } \\
\text { del } \\
\text { Pulso - } \\
\mathrm{Tp}(\mathrm{s}) \\
\end{array}$ & $\begin{array}{l}\text { Duración } \\
5-95 \% \\
\text { (s) }\end{array}$ & $\begin{array}{c}\text { Intensidad } \\
\text { de Arias } \\
(\mathrm{m} / \mathrm{s})\end{array}$ & $\begin{array}{l}\text { Nombre del } \\
\text { sismo }\end{array}$ & Año & Magnitud & $\begin{array}{l}\text { Mecanismo de } \\
\text { falla }\end{array}$ & $\begin{array}{l}\text { Distancia } \\
\text { desde la } \\
\text { falla }(\mathrm{km})\end{array}$ & $\operatorname{Vs} 30(\mathrm{~m} / \mathrm{s})$ \\
\hline 57 & 1.1137 & - & 16.8 & 1 & $\begin{array}{l}\text { "San Fernando" } \\
\text { "Imperial }\end{array}$ & 1971 & 6.61 & Reverse & 19.33 & 450.28 \\
\hline 164 & 1.3199 & - & 36.4 & 1.3 & $\begin{array}{l}\text { Valley-06" } \\
\text { "Victoria_ }\end{array}$ & 1979 & 6.53 & strike slip & 15.19 & 471.53 \\
\hline 265 & 0.7646 & - & 8.2 & 2 & $\begin{array}{l}\text { Mexico" } \\
\text { "Chalfant }\end{array}$ & 1980 & 6.33 & strike slip & 13.8 & 471.53 \\
\hline 548 & 1.5964 & - & 16.6 & 0.4 & Valley-02" & 1986 & 6.19 & strike slip & 21.55 & 370.94 \\
\hline 802 & 0.7971 & 4.571 & 9.4 & 1.5 & $\begin{array}{l}\text { "Loma Prieta" } \\
\text { "Chi-Chi_ }\end{array}$ & 1989 & 6.93 & Reverse Oblique & 7.58 & 380.89 \\
\hline 1193 & 0.9691 & 6.65 & 27 & 1.8 & $\begin{array}{l}\text { Taiwan" } \\
\text { "Chi-Chi_ }\end{array}$ & 1999 & 7.62 & Reverse Oblique & 9.62 & 427.73 \\
\hline 1476 & 1.5682 & 5.285 & 22.3 & 0.8 & $\begin{array}{l}\text { Taiwan" } \\
\text { "Chi-Chi__ }\end{array}$ & 1999 & 7.62 & Reverse Oblique & 28.04 & 406.53 \\
\hline 1478 & 1.3553 & 8.974 & 26.7 & 0.8 & $\begin{array}{l}\text { Taiwan" } \\
\text { "Chi-Chi__ }\end{array}$ & 1999 & 7.62 & Reverse Oblique & 40.88 & 423.4 \\
\hline 1511 & 0.6687 & 4.732 & 29.5 & 3.7 & $\begin{array}{l}\text { Taiwan" } \\
\text { "Chi-Chi_ }\end{array}$ & 1999 & 7.62 & Reverse Oblique & 2.74 & 614.98 \\
\hline 1528 & 1.0681 & 10.318 & 19.2 & 1 & $\begin{array}{l}\text { Taiwan" } \\
\text { "Chi-Chi__ }\end{array}$ & 1999 & 7.62 & Reverse Oblique & 2.11 & 389.41 \\
\hline 2734 & 0.635 & 2.436 & 7.4 & 1.6 & Taiwan-04" & 1999 & 6.2 & strike slip & 6.02 & 553.43 \\
\hline 4228 & 0.6443 & 1.799 & 12.2 & 2.2 & "Niigata_Japan" & 2004 & 6.63 & Reverse & 6.27 & 375 \\
\hline
\end{tabular}

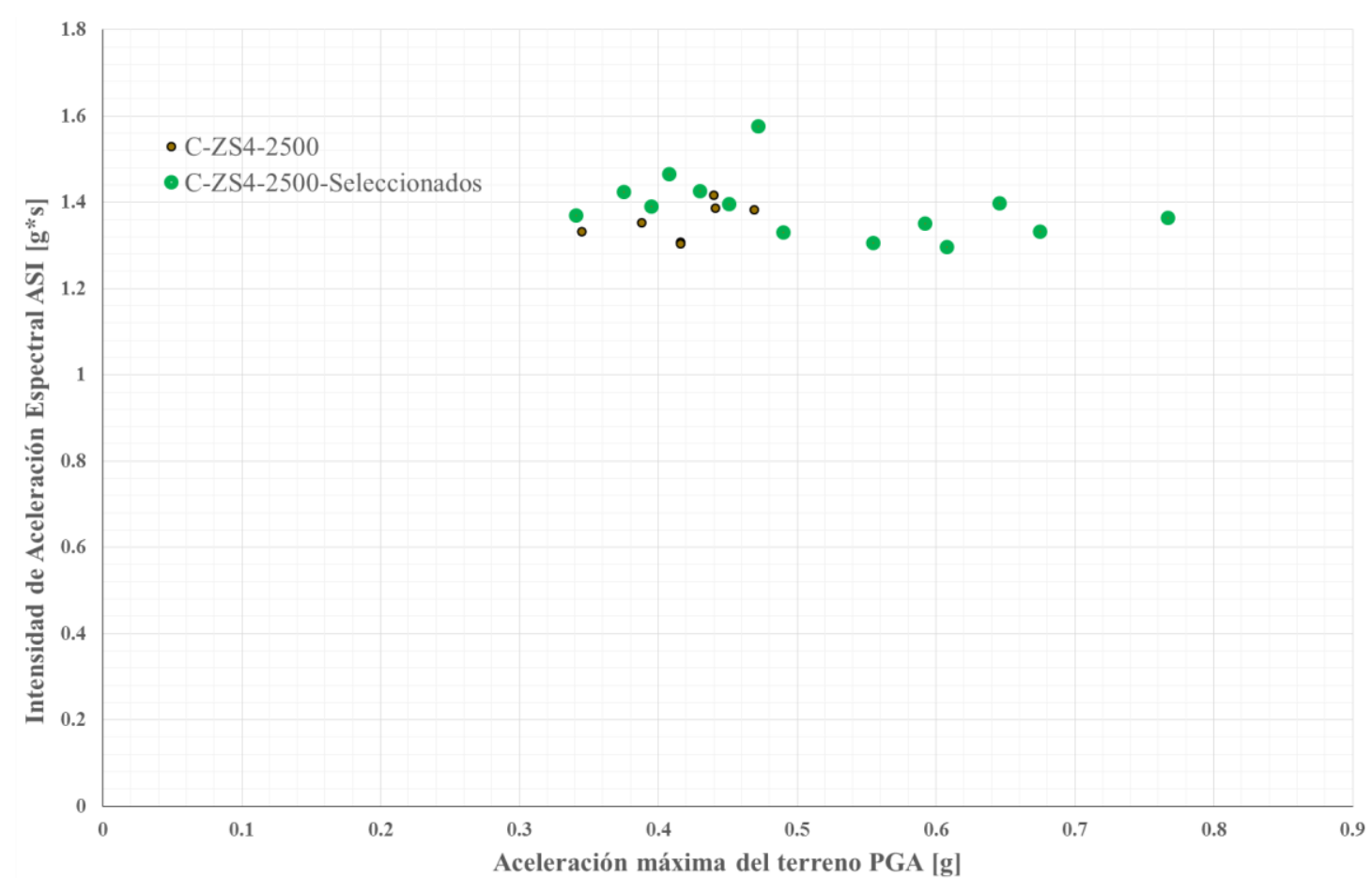

Figura 21. Distribución ASI versus PGA para los sismos de clase de sitio C, zona sísmica 4 y nivel de amenaza sísmica de 2500 años 
Tabla 11. Algunos parámetros importantes de los sismos seleccionados correspondientes a clase de sitio C, zona sísmica 4 y nivel de amenaza sísmica de 2500 años

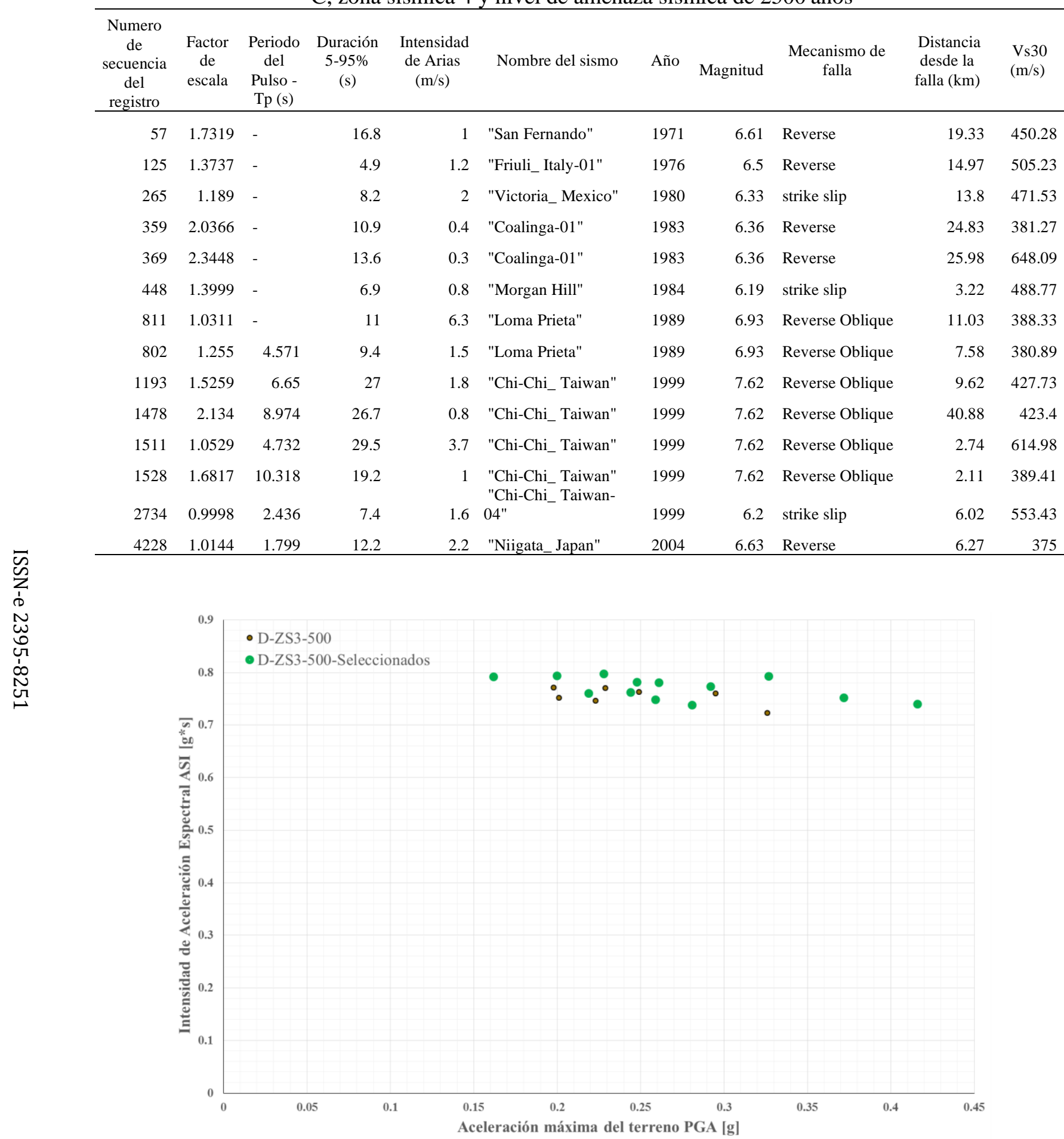

Figura 22. Distribución ASI versus PGA para los sismos de clase de sitio D, zona sísmica 3 y nivel de amenaza sísmica de 500 años 
Tabla 12. Algunos parámetros importantes de los sismos seleccionados correspondientes a clase de sitio D, zona sísmica 3 y nivel de amenaza sísmica de 500 años

\begin{tabular}{|c|c|c|c|c|c|c|c|c|c|c|}
\hline $\begin{array}{l}\text { Numero } \\
\text { de } \\
\text { secuencia } \\
\text { del } \\
\text { registro }\end{array}$ & $\begin{array}{l}\text { Factor } \\
\text { de } \\
\text { escala }\end{array}$ & $\begin{array}{l}\text { Periodo } \\
\text { del } \\
\text { Pulso - } \\
\text { Tp (s) }\end{array}$ & $\begin{array}{c}\text { Duración } \\
5-95 \% \\
\text { (s) }\end{array}$ & $\begin{array}{c}\text { Intensidad } \\
\text { de Arias } \\
(\mathrm{m} / \mathrm{s})\end{array}$ & $\begin{array}{l}\text { Nombre del } \\
\text { sismo }\end{array}$ & Año & Magnitud & $\begin{array}{l}\text { Mecanismo de } \\
\text { falla }\end{array}$ & $\begin{array}{l}\text { Distancia } \\
\text { desde la } \\
\text { falla }(\mathrm{km})\end{array}$ & $\mathrm{Vs} 30(\mathrm{~m} / \mathrm{s})$ \\
\hline 138 & 1.8941 & - & 19.5 & 0.3 & $\begin{array}{l}\text { "Tabas_Iran" } \\
\text { "Imperial }\end{array}$ & 1978 & 7.35 & Reverse & 24.07 & 324.57 \\
\hline 169 & 0.7459 & - & 51.4 & 3.3 & $\begin{array}{l}\text { Valley-06" } \\
\text { "Imperial }\end{array}$ & 1979 & 6.53 & strike slip & 22.03 & 242.05 \\
\hline 175 & 1.6833 & - & 19.6 & 0.4 & $\begin{array}{l}\text { Valley-06" } \\
\text { "Imperial }\end{array}$ & 1979 & 6.53 & strike slip & 17.94 & 196.88 \\
\hline 183 & 0.6099 & - & 6.8 & 1.6 & $\begin{array}{l}\text { Valley-06" } \\
\text { "Imperial }\end{array}$ & 1979 & 6.53 & strike slip & 3.86 & 206.08 \\
\hline 187 & 2.0254 & - & 18.6 & 0.2 & Valley-06" & 1979 & 6.53 & strike slip & 12.69 & 348.69 \\
\hline 328 & 2.2308 & - & 23.5 & 0.2 & $\begin{array}{l}\text { "Coalinga-01" } \\
\text { "Imperial }\end{array}$ & 1983 & 6.36 & Reverse & 44.82 & 230.57 \\
\hline 179 & 0.6027 & 4.788 & 10.3 & 1.4 & $\begin{array}{l}\text { Valley-06" } \\
\text { "Imperial }\end{array}$ & 1979 & 6.53 & strike slip & 4.9 & 208.91 \\
\hline 180 & 0.5305 & 4.13 & 9.6 & 1.7 & $\begin{array}{l}\text { Valley-06" } \\
\text { "Imperial }\end{array}$ & 1979 & 6.53 & strike slip & 1.76 & 205.63 \\
\hline 184 & 0.538 & 6.265 & 7 & 2.1 & $\begin{array}{l}\text { Valley-06" } \\
\text { "Chi-Chi_ }\end{array}$ & 1979 & 6.53 & strike slip & 5.09 & 202.26 \\
\hline 1481 & 1.118 & 9.576 & 28.3 & 1 & $\begin{array}{l}\text { Taiwan" } \\
\text { "Chi-Chi_ }\end{array}$ & 1999 & 7.62 & Reverse Oblique & 25.42 & 297.86 \\
\hline 1491 & 1.0526 & 10.381 & 28.9 & 1.2 & $\begin{array}{l}\text { Taiwan" } \\
\text { "Parkfield-02_ }\end{array}$ & 1999 & 7.62 & Reverse Oblique & 7.64 & 350.06 \\
\hline 4098 & 0.7436 & 1.33 & 7.1 & 0.6 & $\begin{array}{l}\text { CA" } \\
\text { "El Mayor- } \\
\text { Cucapah_- }\end{array}$ & 2004 & 6 & strike slip & 1.66 & 326.64 \\
\hline 8161 & 0.5604 & 8.722 & 32.9 & 3.2 & Mexico" & 2010 & 7.2 & strike slip & 9.98 & 196.88 \\
\hline
\end{tabular}

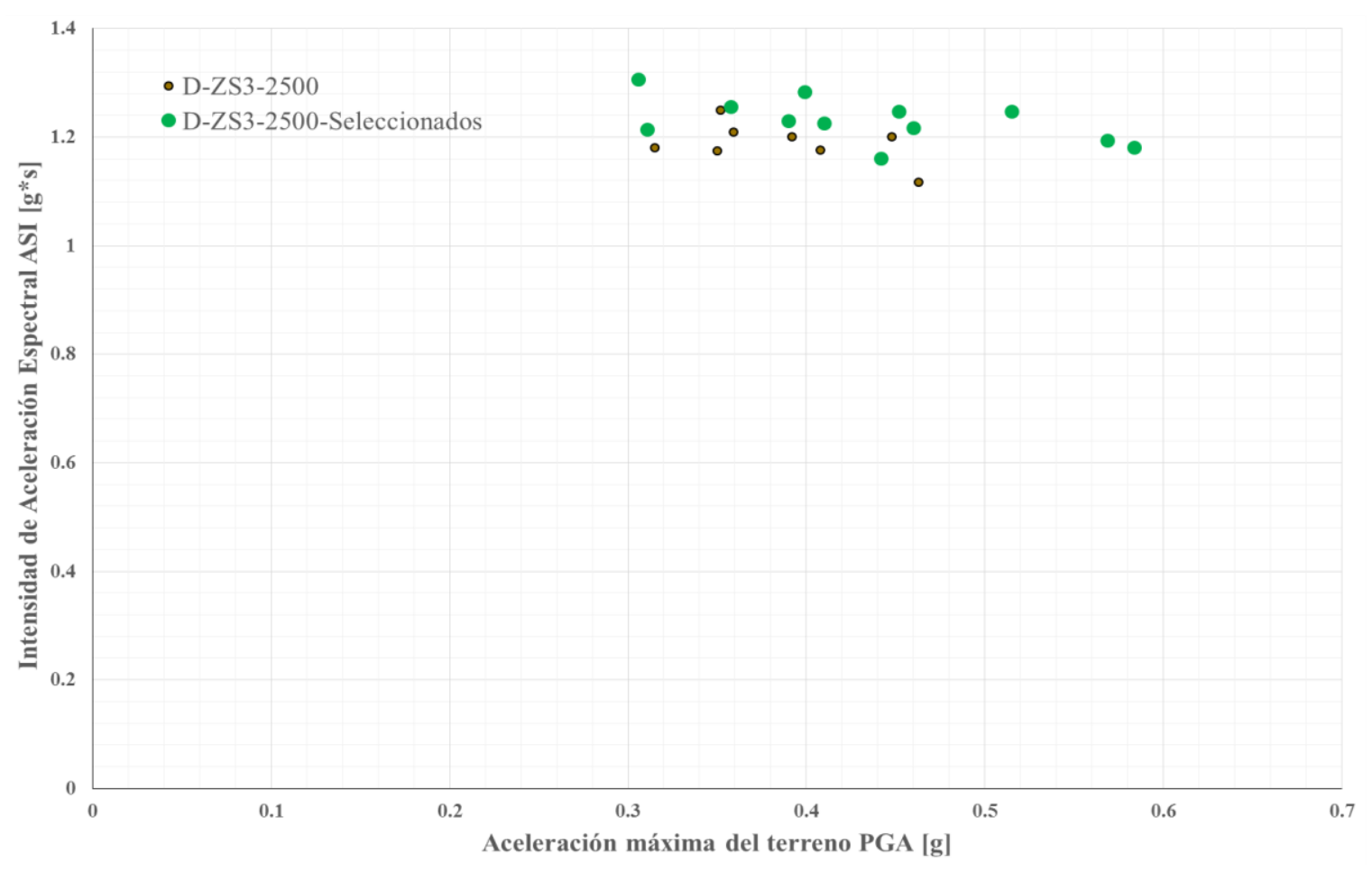

Figura 23. Distribución ASI versus PGA para los sismos de clase de sitio D, zona sísmica 3 y nivel de amenaza sísmica de 2500 años 
Tabla 13. Algunos parámetros importantes de los sismos seleccionados correspondientes a clase de sitio $\mathrm{D}$, zona sísmica 3 y nivel de amenaza sísmica de 2500 años

\begin{tabular}{|c|c|c|c|c|c|c|c|c|c|c|}
\hline $\begin{array}{l}\text { Numero } \\
\text { de } \\
\text { secuencia } \\
\text { del } \\
\text { registro }\end{array}$ & $\begin{array}{l}\text { Factor } \\
\text { de } \\
\text { escala }\end{array}$ & $\begin{array}{c}\text { Periodo } \\
\text { del } \\
\text { Pulso - } \\
\mathrm{Tp}(\mathrm{s})\end{array}$ & $\begin{array}{l}\text { Duración } \\
5-95 \% \\
\text { (s) }\end{array}$ & $\begin{array}{c}\text { Intensidad } \\
\text { de Arias } \\
(\mathrm{m} / \mathrm{s})\end{array}$ & $\begin{array}{l}\text { Nombre del } \\
\text { sismo }\end{array}$ & Año & Magnitud & $\begin{array}{l}\text { Mecanismo de } \\
\text { falla }\end{array}$ & $\begin{array}{l}\text { Distancia } \\
\text { desde la } \\
\text { falla }(\mathrm{km})\end{array}$ & $\mathrm{Vs} 30(\mathrm{~m} / \mathrm{s})$ \\
\hline 126 & 0.6589 & - & 7 & 5.7 & $\begin{array}{l}\text { "Gazli_USSR" } \\
\text { "Imperial }\end{array}$ & 1976 & 6.8 & Reverse & 3.92 & 259.59 \\
\hline 169 & 1.1716 & - & 51.4 & 3.3 & $\begin{array}{l}\text { Valley-06" } \\
\text { "Imperial }\end{array}$ & 1979 & 6.53 & strike slip & 22.03 & 242.05 \\
\hline 183 & 0.958 & - & 6.8 & 1.6 & Valley-06" & 1979 & 6.53 & strike slip & 3.86 & 206.08 \\
\hline 339 & 2.0657 & - & 19.7 & 0.5 & "Coalinga-01" & 1983 & 6.36 & Reverse & 28 & 307.59 \\
\hline 346 & 2.2942 & - & 12.7 & 0.3 & "Coalinga-01" & 1983 & 6.36 & Reverse & 28.58 & 308.84 \\
\hline 461 & 1.4468 & - & 15.3 & 0.9 & $\begin{array}{l}\text { "Morgan Hill" } \\
\text { "Imperial }\end{array}$ & 1984 & 6.19 & strike slip & 3.45 & 281.61 \\
\hline 179 & 0.9485 & 4.788 & 10.3 & 1.4 & $\begin{array}{l}\text { Valley-06" } \\
\text { "Imperial }\end{array}$ & 1979 & 6.53 & strike slip & 4.9 & 208.91 \\
\hline 180 & 0.8349 & 4.13 & 9.6 & 1.7 & $\begin{array}{l}\text { Valley-06" } \\
\text { "Chi-Chi_ }\end{array}$ & 1979 & 6.53 & strike slip & 1.76 & 205.63 \\
\hline 1491 & 1.6565 & 10.381 & 28.9 & 1.2 & $\begin{array}{l}\text { Taiwan" } \\
\text { "Parkfield-02__ }\end{array}$ & 1999 & 7.62 & Reverse Oblique & 7.64 & 350.06 \\
\hline 4098 & 1.1702 & 1.33 & 7.1 & 0.6 & $\begin{array}{l}\text { CA" } \\
\text { "Darfield_New }\end{array}$ & 2004 & 6 & strike slip & 1.66 & 326.64 \\
\hline 6966 & 1.6186 & 8.757 & 26.4 & 1 & $\begin{array}{l}\text { Zealand" } \\
\text { "El Mayor- } \\
\text { Cucapah__ }\end{array}$ & 2010 & 7 & strike slip & 22.33 & 207 \\
\hline 8161 & 0.882 & 8.722 & 32.9 & 3.2 & Mexico" & 2010 & 7.2 & strike slip & 9.98 & 196.88 \\
\hline
\end{tabular}

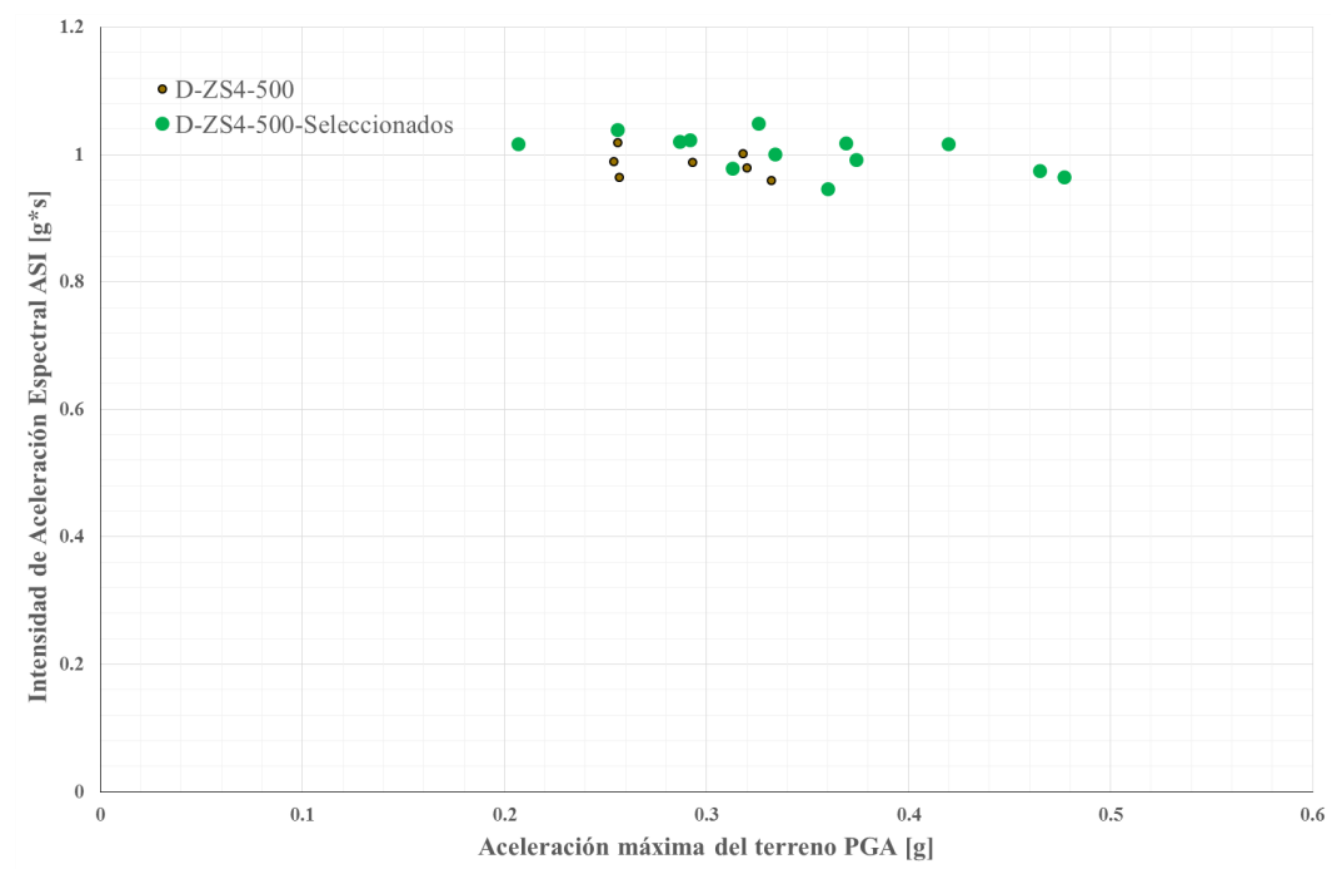

Figura 24. Distribución ASI versus PGA para los sismos de clase de sitio D, zona sísmica 4 y nivel de amenaza sísmica de 500 años 
Tabla 14. Algunos parámetros importantes de los sismos seleccionados correspondientes a clase de sitio $\mathrm{D}$, zona sísmica 4 y nivel de amenaza sísmica de 500 años

\begin{tabular}{|c|c|c|c|c|c|c|c|c|c|c|}
\hline $\begin{array}{l}\text { Numero } \\
\text { de } \\
\text { secuencia } \\
\text { del } \\
\text { registro }\end{array}$ & $\begin{array}{l}\text { Factor } \\
\text { de } \\
\text { escala }\end{array}$ & $\begin{array}{c}\text { Periodo } \\
\text { del } \\
\text { Pulso - } \\
\text { Tp (s) }\end{array}$ & $\begin{array}{l}\text { Duración } \\
5-95 \% \\
\text { (s) }\end{array}$ & $\begin{array}{c}\text { Intensidad } \\
\text { de Arias } \\
(\mathrm{m} / \mathrm{s})\end{array}$ & $\begin{array}{l}\text { Nombre del } \\
\text { sismo }\end{array}$ & Año & Magnitud & $\begin{array}{l}\text { Mecanismo de } \\
\text { falla }\end{array}$ & $\begin{array}{l}\text { Distancia } \\
\text { desde la } \\
\text { falla }(\mathrm{km})\end{array}$ & $\mathrm{Vs} 30(\mathrm{~m} / \mathrm{s})$ \\
\hline 126 & 0.538 & - & 7 & 5.7 & $\begin{array}{l}\text { "Gazli_USSR" } \\
\text { "Imperial }\end{array}$ & 1976 & 6.8 & Reverse & 3.92 & 259.59 \\
\hline 165 & 1.0648 & - & 24 & 1.2 & $\begin{array}{l}\text { Valley-06" } \\
\text { "Imperial }\end{array}$ & 1979 & 6.53 & strike slip & 7.29 & 242.05 \\
\hline 169 & 0.9567 & - & 51.4 & 3.3 & $\begin{array}{l}\text { Valley-06" } \\
\text { "Imperial }\end{array}$ & 1979 & 6.53 & strike slip & 22.03 & 242.05 \\
\hline 175 & 2.159 & - & 19.6 & 0.4 & $\begin{array}{l}\text { Valley-06" } \\
\text { "Imperial }\end{array}$ & 1979 & 6.53 & strike slip & 17.94 & 196.88 \\
\hline 183 & 0.7822 & - & 6.8 & 1.6 & Valley-06" & 1979 & 6.53 & strike slip & 3.86 & 206.08 \\
\hline 339 & 1.6867 & - & 19.7 & 0.5 & "Coalinga-01" & 1983 & 6.36 & Reverse & 28 & 307.59 \\
\hline 461 & 1.1813 & - & 15.3 & 0.9 & $\begin{array}{l}\text { "Morgan Hill" } \\
\text { "Imperial }\end{array}$ & 1984 & 6.19 & strike slip & 3.45 & 281.61 \\
\hline 179 & 0.7729 & 4.788 & 10.3 & 1.4 & $\begin{array}{l}\text { Valley-06" } \\
\text { "Imperial }\end{array}$ & 1979 & 6.53 & strike slip & 4.9 & 208.91 \\
\hline 180 & 0.6803 & 4.13 & 9.6 & 1.7 & $\begin{array}{l}\text { Valley-06" } \\
\text { "Chi-Chi_ }\end{array}$ & 1979 & 6.53 & strike slip & 1.76 & 205.63 \\
\hline 1481 & 1.4337 & 9.576 & 28.3 & 1 & $\begin{array}{l}\text { Taiwan" } \\
\text { "Parkfield-02_ }\end{array}$ & 1999 & 7.62 & Reverse Oblique & 25.42 & 297.86 \\
\hline 4098 & 0.9535 & 1.33 & 7.1 & 0.6 & $\begin{array}{l}\text { CA" } \\
\text { "Darfield_New }\end{array}$ & 2004 & 6 & strike slip & 1.66 & 326.64 \\
\hline 6969 & 1.4534 & 9.352 & 38.2 & 0.9 & $\begin{array}{l}\text { Zealand" } \\
\text { "El Mayor- } \\
\text { Cucapah__ }\end{array}$ & 2010 & 7 & strike slip & 20.86 & 247.5 \\
\hline 8161 & 0.7187 & 8.722 & 32.9 & 3.2 & Mexico" & 2010 & 7.2 & strike slip & 9.98 & 196.88 \\
\hline
\end{tabular}

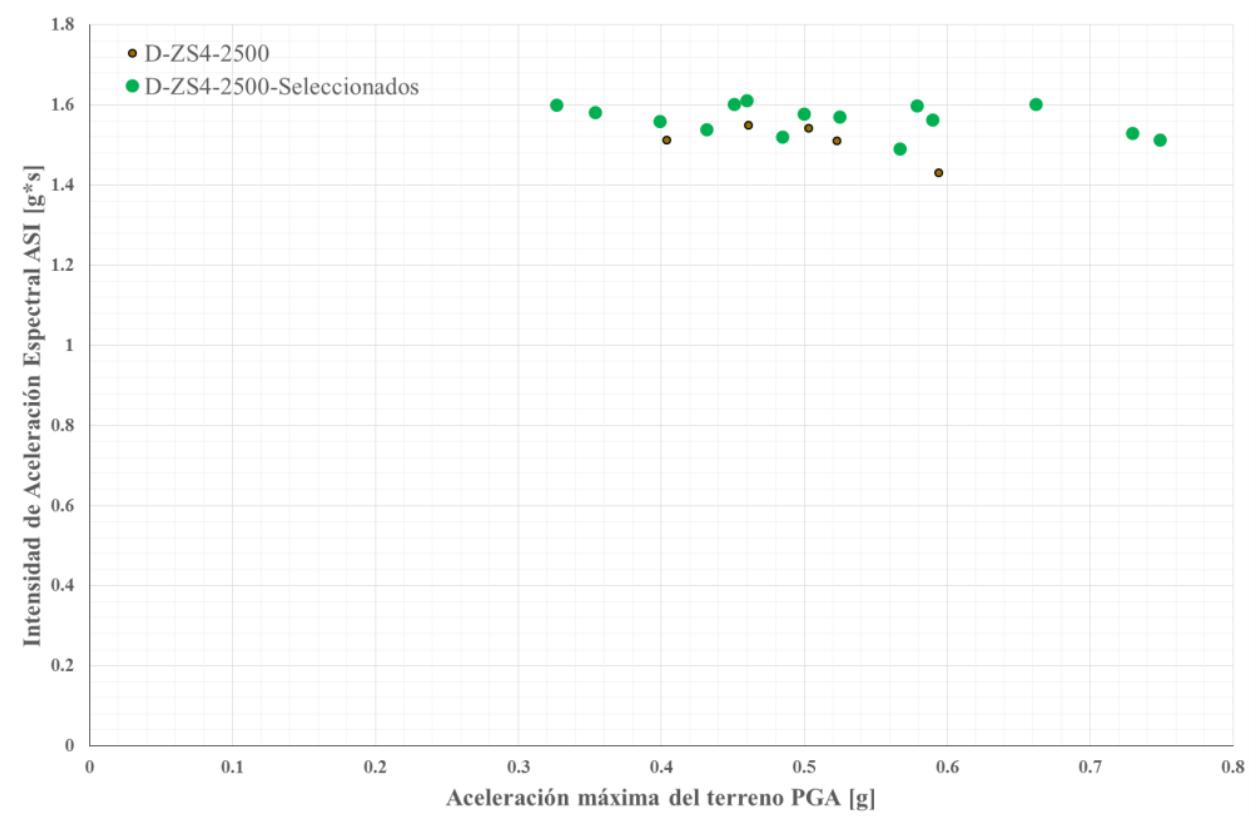

Figura 25. Distribución ASI versus PGA para los sismos de clase de sitio D, zona sísmica 4 y nivel de amenaza sísmica de 2500 años 
Tabla 15. Algunos parámetros importantes de los sismos seleccionados correspondientes a clase de sitio $\mathrm{D}$, zona sísmica 4 y nivel de amenaza sísmica de 2500 años

\begin{tabular}{|c|c|c|c|c|c|c|c|c|c|c|}
\hline $\begin{array}{l}\text { Numero } \\
\text { de } \\
\text { secuencia } \\
\text { del } \\
\text { registro }\end{array}$ & $\begin{array}{l}\text { Factor } \\
\text { de } \\
\text { escala }\end{array}$ & $\begin{array}{c}\text { Periodo } \\
\text { del } \\
\text { Pulso - } \\
\text { Tp (s) }\end{array}$ & $\begin{array}{l}\text { Duración } \\
5-95 \% \\
\text { (s) }\end{array}$ & $\begin{array}{l}\text { Intensidad } \\
\text { de Arias } \\
(\mathrm{m} / \mathrm{s})\end{array}$ & $\begin{array}{l}\text { Nombre del } \\
\text { sismo }\end{array}$ & Año & Magnitud & $\begin{array}{c}\text { Mecanismo de } \\
\text { falla }\end{array}$ & $\begin{array}{l}\text { Distancia } \\
\text { desde la } \\
\text { falla }(\mathrm{km})\end{array}$ & $\mathrm{Vs} 30(\mathrm{~m} / \mathrm{s})$ \\
\hline 126 & 0.8446 & - & 7 & 5.7 & $\begin{array}{l}\text { "Gazli_USSR" } \\
\text { "Imperial }\end{array}$ & 1976 & 6.8 & Reverse & 3.92 & 259.59 \\
\hline 165 & 1.6714 & - & 24 & 1.2 & $\begin{array}{l}\text { Valley-06" } \\
\text { "Imperial }\end{array}$ & 1979 & 6.53 & strike slip & 7.29 & 242.05 \\
\hline 169 & 1.5017 & - & 51.4 & 3.3 & $\begin{array}{l}\text { Valley-06" } \\
\text { "Imperial }\end{array}$ & 1979 & 6.53 & strike slip & 22.03 & 242.05 \\
\hline 183 & 1.2279 & - & 6.8 & 1.6 & Valley-06" & 1979 & 6.53 & strike slip & 3.86 & 206.08 \\
\hline 322 & 1.4972 & - & 12.6 & 1.2 & "Coalinga-01" & 1983 & 6.36 & Reverse & 23.78 & 274.73 \\
\hline 368 & 0.8047 & - & 9.1 & 4.1 & "Coalinga-01" & 1983 & 6.36 & Reverse & 7.69 & 257.38 \\
\hline 461 & 1.8544 & - & 15.3 & 0.9 & $\begin{array}{l}\text { "Morgan Hill" } \\
\text { "Imperial }\end{array}$ & 1984 & 6.19 & strike slip & 3.45 & 281.61 \\
\hline 179 & 1.2175 & 4.788 & 10.3 & 1.4 & $\begin{array}{l}\text { Valley-06" } \\
\text { "Imperial }\end{array}$ & 1979 & 6.53 & strike slip & 4.9 & 208.91 \\
\hline 180 & 1.0717 & 4.13 & 9.6 & 1.7 & Valley-06" & 1979 & 6.53 & strike slip & 1.76 & 205.63 \\
\hline 1044 & 0.5994 & 1.372 & 5.9 & 5.7 & $\begin{array}{l}\text { "Northridge-01" } \\
\text { "Chi-Chi__ }\end{array}$ & 1994 & 6.69 & Reverse & 3.16 & 269.14 \\
\hline 1481 & 2.2584 & 9.576 & 28.3 & 1 & $\begin{array}{l}\text { Taiwan" } \\
\text { "Chi-Chi__ }\end{array}$ & 1999 & 7.62 & Reverse Oblique & 25.42 & 297.86 \\
\hline 1491 & 2.1263 & 10.381 & 28.9 & 1.2 & $\begin{array}{l}\text { Taiwan" } \\
\text { "Parkfield-02_ }\end{array}$ & 1999 & 7.62 & Reverse Oblique & 7.64 & 350.06 \\
\hline 4098 & 1.502 & 1.33 & 7.1 & 0.6 & $\begin{array}{l}\text { CA" } \\
\text { "Darfield_New }\end{array}$ & 2004 & 6 & strike slip & 1.66 & 326.64 \\
\hline 6966 & 2.0777 & 8.757 & 26.4 & 1 & $\begin{array}{l}\text { Zealand" } \\
\text { "El Mayor- } \\
\text { Cucapah_ }\end{array}$ & 2010 & 7 & strike slip & 22.33 & 207 \\
\hline 8161 & 1.1321 & 8.722 & 32.9 & 3.2 & Mexico" & 2010 & 7.2 & strike slip & 9.98 & 196.88 \\
\hline
\end{tabular}

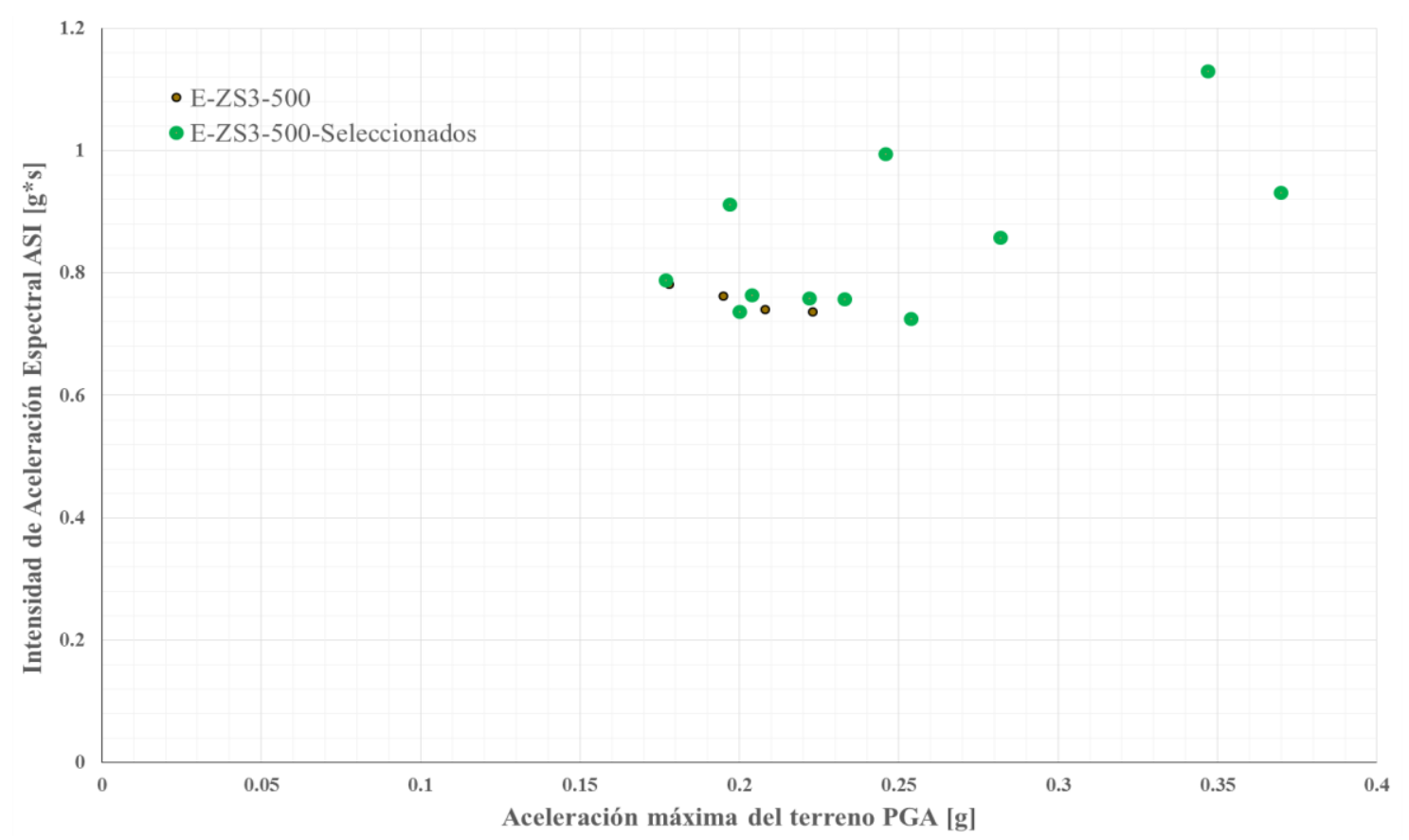

Figura 26. Distribución ASI versus PGA para los sismos de clase de sitio E, zona sísmica 3 y nivel de amenaza sísmica de 500 años 
Tabla 16. Algunos parámetros importantes de los sismos seleccionados correspondientes a clase de sitio E, zona sísmica 3 y nivel de amenaza sísmica de 500 años

\begin{tabular}{|c|c|c|c|c|c|c|c|c|c|c|}
\hline $\begin{array}{l}\text { Numero } \\
\text { de } \\
\text { secuencia } \\
\text { del } \\
\text { registro }\end{array}$ & $\begin{array}{l}\text { Factor } \\
\text { de } \\
\text { escala }\end{array}$ & $\begin{array}{c}\text { Periodo } \\
\text { del } \\
\text { Pulso - } \\
\mathrm{Tp}(\mathrm{s}) \\
\end{array}$ & $\begin{array}{l}\text { Duración } \\
5-95 \% \\
\text { (s) }\end{array}$ & $\begin{array}{l}\text { Intensidad } \\
\text { de Arias } \\
(\mathrm{m} / \mathrm{s})\end{array}$ & $\begin{array}{l}\text { Nombre del } \\
\text { sismo }\end{array}$ & Año & Magnitud & $\begin{array}{l}\text { Mecanismo de } \\
\text { falla }\end{array}$ & $\begin{array}{l}\text { Distancia } \\
\text { desde la } \\
\text { falla }(\mathrm{km})\end{array}$ & $\operatorname{Vs} 30(\mathrm{~m} / \mathrm{s})$ \\
\hline 718 & 1.9137 & - & 15.2 & 0.3 & $\begin{array}{l}\text { "Superstition } \\
\text { Hills-01" } \\
\text { "Chi-Chi }\end{array}$ & 1987 & 6.22 & strike slip & 17.59 & 179 \\
\hline 1209 & 1.1011 & - & 34.9 & 1.1 & $\begin{array}{l}\text { Taiwan" } \\
\text { "Chi-Chi_ }\end{array}$ & 1999 & 7.62 & Reverse Oblique & 24.13 & 169.52 \\
\hline 1228 & 2.4432 & - & 42 & 0.3 & $\begin{array}{l}\text { Taiwan" } \\
\text { "Chi-Chi__ }\end{array}$ & 1999 & 7.62 & Reverse Oblique & 42.15 & 169.84 \\
\hline 2715 & 1.6715 & - & 17.2 & 0.2 & Taiwan-04" & 1999 & 6.2 & strike slip & 38.59 & 169.52 \\
\hline 4203 & 1.6932 & - & 73.5 & 0.5 & $\begin{array}{l}\text { "Niigata_Japan" } \\
\text { "Chuetsu-oki_ }\end{array}$ & 2004 & 6.63 & Reverse & 38 & 174.55 \\
\hline 5259 & 1.5654 & - & 70 & 0.5 & $\begin{array}{l}\text { Japan" } \\
\text { "El Mayor- } \\
\text { Cucapah_ }\end{array}$ & 2007 & 6.8 & Reverse & 27.92 & 174.55 \\
\hline 5989 & 1.1167 & - & 68.9 & 1 & $\begin{array}{l}\text { Mexico" } \\
\text { "Imperial }\end{array}$ & 2010 & 7.2 & strike slip & 40.96 & 162.94 \\
\hline 178 & 1.0544 & 4.501 & 14.1 & 1.2 & Valley-06" & 1979 & 6.53 & strike slip & 10.79 & 162.94 \\
\hline 3965 & 0.6277 & 1.54 & 18.5 & 1.8 & $\begin{array}{l}\text { "Tottori_Japan" } \\
\text { "Parkfield-02__ }\end{array}$ & 2000 & 6.61 & strike slip & 6.86 & 139.21 \\
\hline 4100 & 0.5929 & 1.078 & 7 & 1.6 & $\begin{array}{l}\text { CA" } \\
\text { "Darfield_New }\end{array}$ & 2004 & 6 & strike slip & 1.63 & 173.02 \\
\hline 6959 & 0.7497 & 12.019 & 30.5 & 1.8 & $\begin{array}{l}\text { Zealand" } \\
\text { "Christchurch__ }\end{array}$ & 2010 & 7 & strike slip & 19.48 & 141 \\
\hline 8123 & 0.4851 & 1.554 & 11.2 & 3.6 & New Zealand" & 2011 & 6.2 & Reverse Oblique & 5.11 & 141 \\
\hline
\end{tabular}

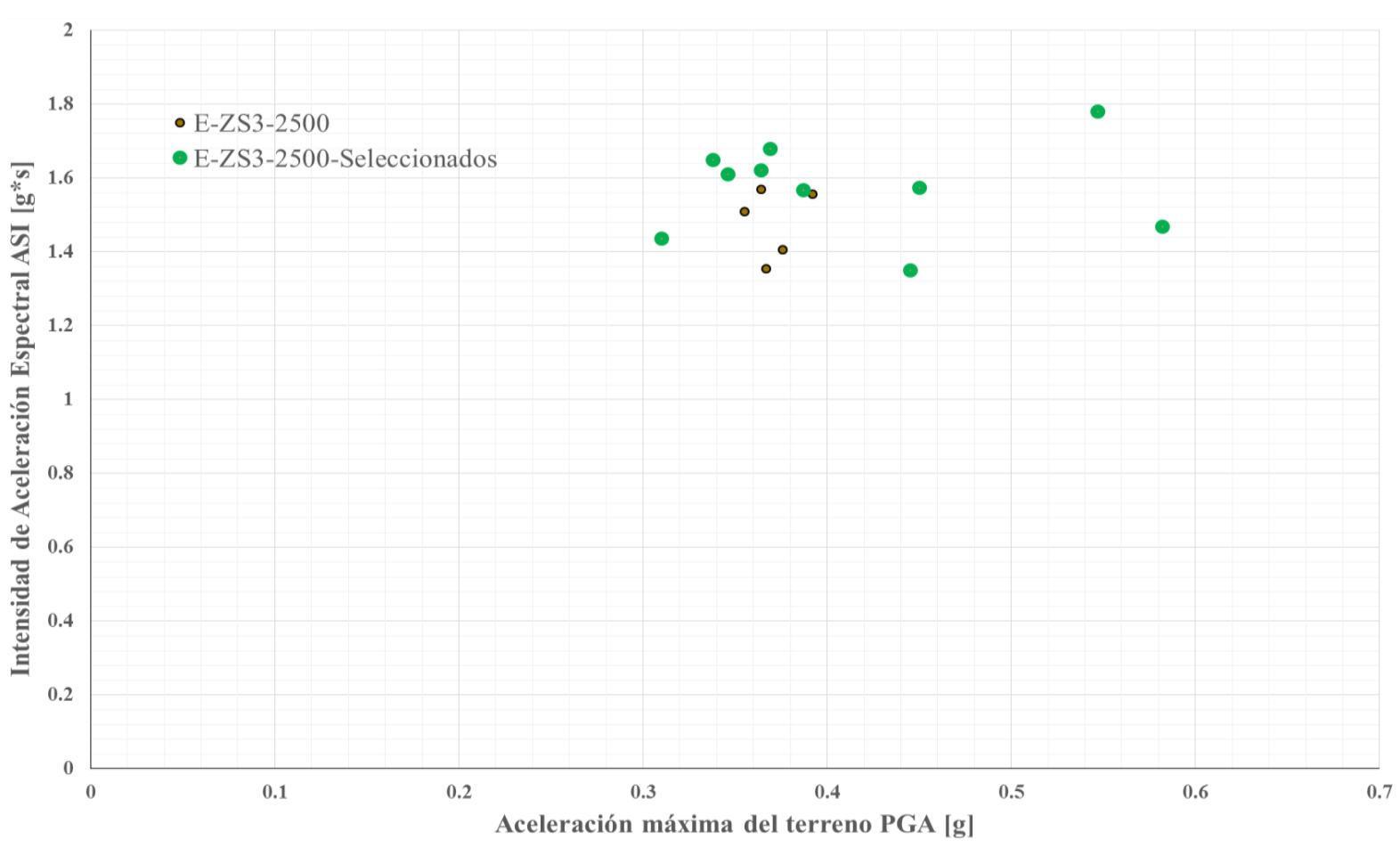

Figura 27. Distribución ASI versus PGA para los sismos de clase de sitio E, zona sísmica 3 y nivel de amenaza sísmica de 2500 años 
Tabla 17. Algunos parámetros importantes de los sismos seleccionados correspondientes a clase de sitio E, zona sísmica 3 y nivel de amenaza sísmica de 2500 años

\begin{tabular}{|c|c|c|c|c|c|c|c|c|c|c|}
\hline $\begin{array}{l}\text { Numero } \\
\text { de } \\
\text { secuencia } \\
\text { del } \\
\text { registro }\end{array}$ & $\begin{array}{l}\text { Factor } \\
\text { de } \\
\text { escala }\end{array}$ & $\begin{array}{c}\text { Periodo } \\
\text { del } \\
\text { Pulso - } \\
\text { Tp (s) }\end{array}$ & $\begin{array}{c}\text { Duración } \\
\text { 5-95\% } \\
\text { (s) }\end{array}$ & $\begin{array}{l}\text { Intensidad } \\
\text { de Arias } \\
(\mathrm{m} / \mathrm{s})\end{array}$ & $\begin{array}{l}\text { Nombre del } \\
\text { sismo }\end{array}$ & Año & Magnitud & $\begin{array}{l}\text { Mecanismo de } \\
\text { falla }\end{array}$ & $\begin{array}{l}\text { Distancia } \\
\text { desde la } \\
\text { falla }(\mathrm{km})\end{array}$ & Vs30 (m/s) \\
\hline 334 & 2.3624 & - & 30.8 & 0.7 & "Coalinga-01" & 1983 & 6.36 & Reverse & 41.04 & 178.27 \\
\hline 759 & 1.2795 & - & 23.1 & 1.8 & "Loma Prieta" & 1989 & 6.93 & Reverse Oblique & 43.77 & 116.35 \\
\hline 808 & 2.3063 & - & 5.8 & 0.4 & $\begin{array}{l}\text { "Loma Prieta" } \\
\text { "Chuetsu-oki_}\end{array}$ & 1989 & 6.93 & Reverse Oblique & 77.32 & 155.11 \\
\hline 5271 & 1.9672 & - & 25.2 & 0.7 & Japan" & 2007 & 6.8 & Reverse & 28.3 & 134.5 \\
\hline 5665 & 1.4273 & - & 45.8 & 1.9 & $\begin{array}{l}\text { "Iwate_Japan" } \\
\text { "Imperial }\end{array}$ & 2008 & 6.9 & Reverse & 30.38 & 146.72 \\
\hline 178 & 1.6605 & 4.501 & 14.1 & 1.2 & Valley-06" & 1979 & 6.53 & strike slip & 10.79 & 162.94 \\
\hline 3965 & 0.9885 & 1.54 & 18.5 & 1.8 & $\begin{array}{l}\text { "Tottori_Japan" } \\
\text { "Parkfield-02_ }\end{array}$ & 2000 & 6.61 & strike slip & 6.86 & 139.21 \\
\hline 4100 & 0.9337 & 1.078 & 7 & 1.6 & $\begin{array}{l}\text { CA" } \\
\text { "Darfield_New }\end{array}$ & 2004 & 6 & strike slip & 1.63 & 173.02 \\
\hline 6959 & 1.1806 & 12.019 & 30.5 & 1.8 & $\begin{array}{l}\text { Zealand" } \\
\text { "Christchurch__ }\end{array}$ & 2010 & 7 & strike slip & 19.48 & 141 \\
\hline 8123 & 0.764 & 1.554 & 11.2 & 3.6 & New Zealand" & 2011 & 6.2 & Reverse Oblique & 5.11 & 141 \\
\hline
\end{tabular}

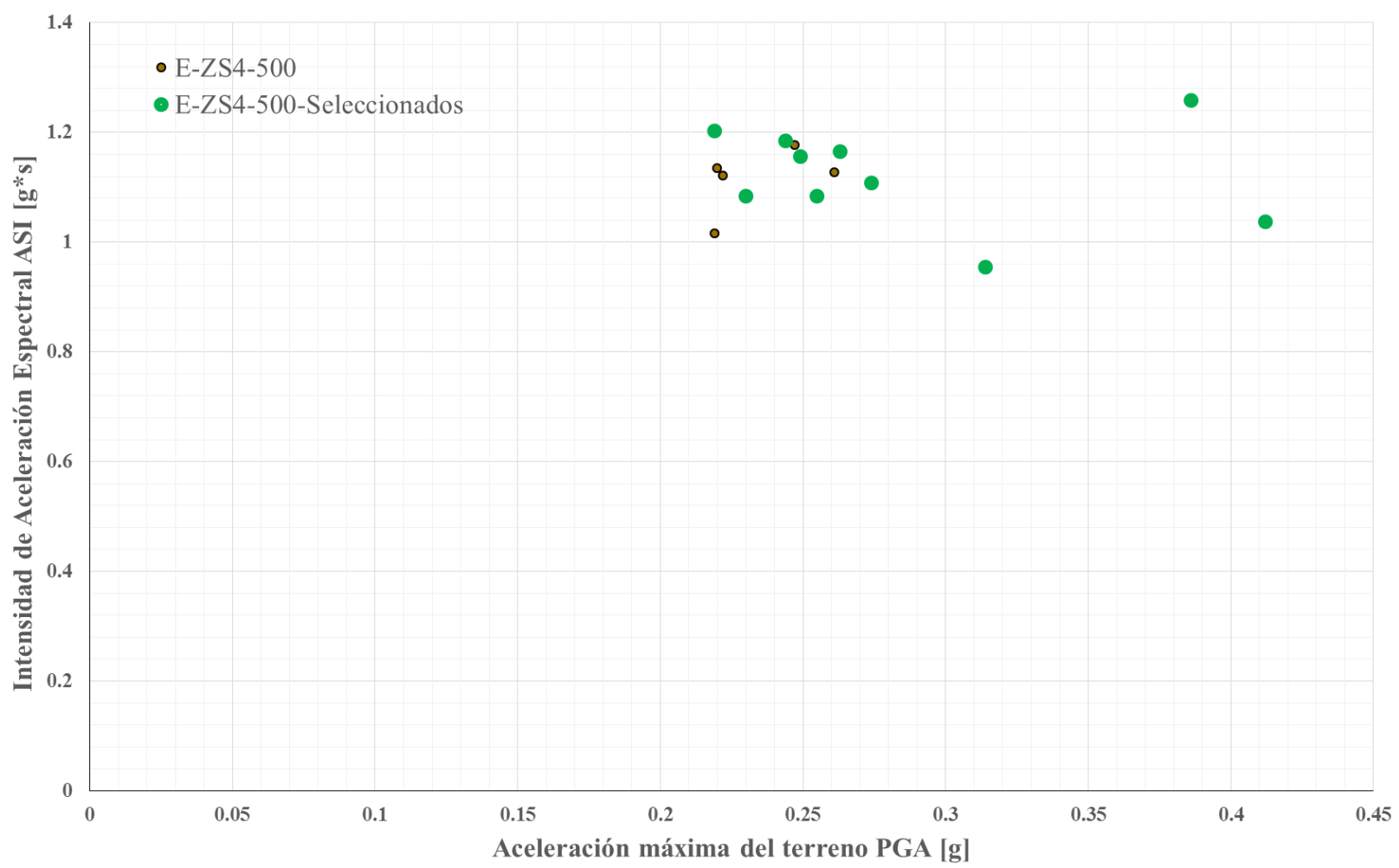

Figura 28. Distribución ASI versus PGA para los sismos de clase de sitio E, zona sísmica 4 y nivel de amenaza sísmica de 500 años 
Tabla 18. Algunos parámetros importantes de los sismos seleccionados correspondientes a clase de sitio E, zona sísmica 4 y nivel de amenaza sísmica de 500 años

\begin{tabular}{|c|c|c|c|c|c|c|c|c|c|c|}
\hline $\begin{array}{l}\text { Numero } \\
\text { de } \\
\text { secuencia } \\
\text { del } \\
\text { registro }\end{array}$ & $\begin{array}{l}\text { Factor } \\
\text { de } \\
\text { escala }\end{array}$ & $\begin{array}{l}\text { Periodo } \\
\text { del } \\
\text { Pulso - } \\
\text { Tp (s) }\end{array}$ & $\begin{array}{c}\text { Duración } \\
5-95 \% \\
\text { (s) }\end{array}$ & $\begin{array}{c}\text { Intensidad } \\
\text { de Arias } \\
(\mathrm{m} / \mathrm{s})\end{array}$ & $\begin{array}{l}\text { Nombre del } \\
\text { sismo }\end{array}$ & Año & Magnitud & $\begin{array}{l}\text { Mecanismo de } \\
\text { falla }\end{array}$ & $\begin{array}{l}\text { Distancia } \\
\text { desde la } \\
\text { falla }(\mathrm{km})\end{array}$ & Vs30 (m/s) \\
\hline 334 & 1.6978 & - & 30.8 & 0.7 & $\begin{array}{l}\text { "Coalinga-01" } \\
\text { "Superstition }\end{array}$ & 1983 & 6.36 & Reverse & 41.04 & 178.27 \\
\hline 729 & 1.23 & - & 35.8 & 1.3 & Hills-02" & 1987 & 6.54 & strike slip & 23.85 & 179 \\
\hline 759 & 0.9196 & - & 23.1 & 1.8 & $\begin{array}{l}\text { "Loma Prieta" } \\
\text { "Chi-Chi_ }\end{array}$ & 1989 & 6.93 & Reverse Oblique & 43.77 & 116.35 \\
\hline 1212 & 2.4086 & - & 39.8 & 0.4 & $\begin{array}{l}\text { Taiwan" } \\
\text { "Chi-Chi_ }\end{array}$ & 1999 & 7.62 & Reverse Oblique & 48.49 & 172.1 \\
\hline 1421 & 2.1789 & - & 28.5 & 0.4 & Taiwan" & 1999 & 7.62 & Reverse Oblique & 99.54 & 167.18 \\
\hline 5665 & 1.0258 & - & 45.8 & 1.9 & $\begin{array}{l}\text { "Iwate_Japan" } \\
\text { "Imperial }\end{array}$ & 2008 & 6.9 & Reverse & 30.38 & 146.72 \\
\hline 178 & 1.1741 & 4.501 & 14.1 & 1.2 & Valley-06" & 1979 & 6.53 & strike slip & 10.79 & 162.94 \\
\hline 3965 & 0.6989 & 1.54 & 18.5 & 1.8 & $\begin{array}{l}\text { "Tottori_Japan" } \\
\text { "Parkfield-02__ }\end{array}$ & 2000 & 6.61 & strike slip & 6.86 & 139.21 \\
\hline 4100 & 0.6602 & 1.078 & 7 & 1.6 & $\begin{array}{l}\text { CA" } \\
\text { "Christchurch_ }\end{array}$ & 2004 & 6 & strike slip & 1.63 & 173.02 \\
\hline 8123 & 0.5402 & 1.554 & 11.2 & 3.6 & New Zealand" & 2011 & 6.2 & Reverse Oblique & 5.11 & 141 \\
\hline
\end{tabular}

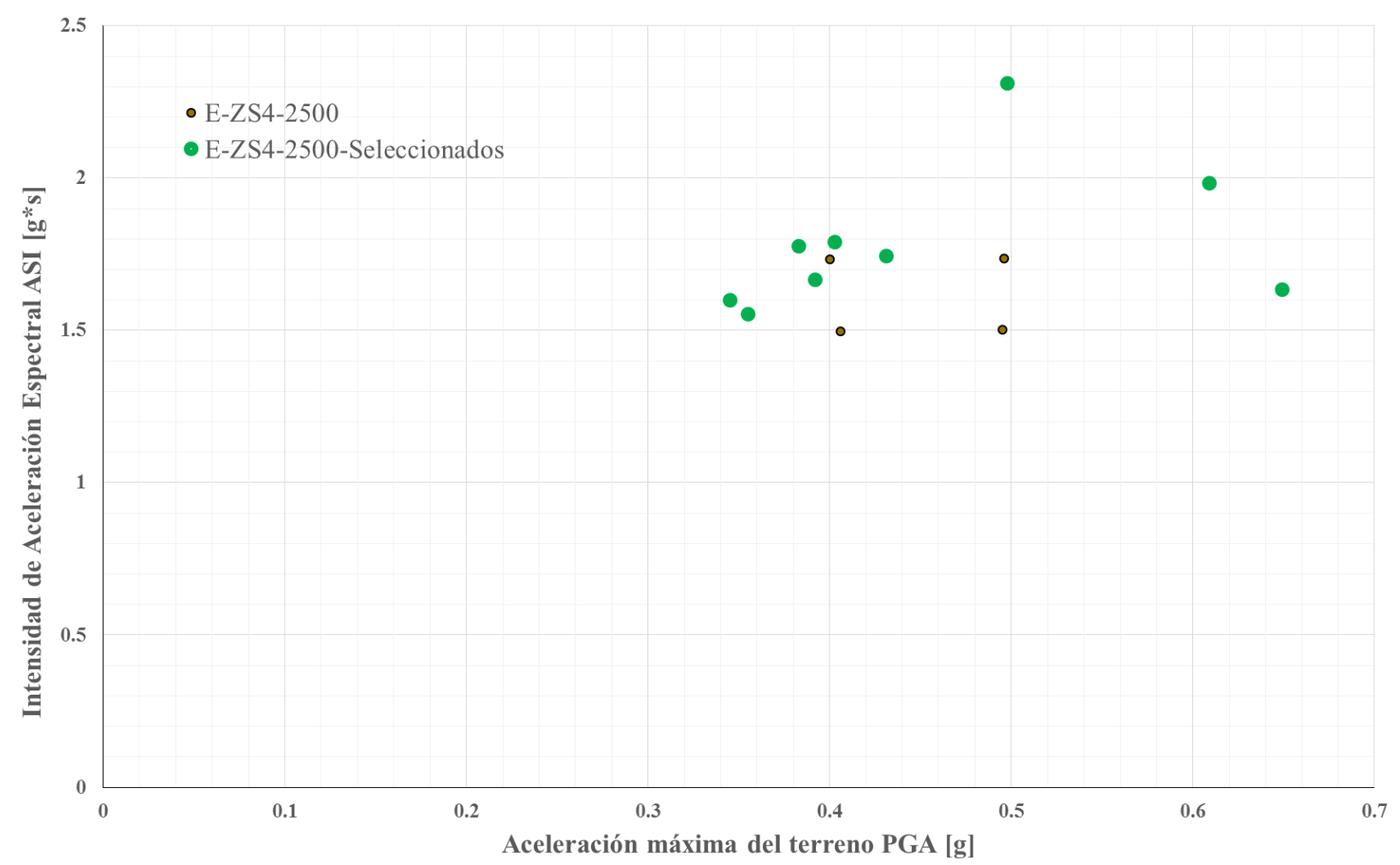

Figura 29. Distribución ASI versus PGA para los sismos de clase de sitio E, zona sísmica 4 y nivel de amenaza sísmica de 2500 años 
Tabla 19. Algunos parámetros importantes de los sismos seleccionados correspondientes a clase de sitio E, zona sísmica 4 y nivel de amenaza sísmica de 2500 años

\begin{tabular}{|c|c|c|c|c|c|c|c|c|c|c|}
\hline $\begin{array}{l}\text { Numero } \\
\text { de } \\
\text { secuencia } \\
\text { del } \\
\text { registro }\end{array}$ & $\begin{array}{l}\text { Factor } \\
\text { de } \\
\text { escala }\end{array}$ & $\begin{array}{c}\text { Periodo } \\
\text { del } \\
\text { Pulso - } \\
\text { Tp (s) }\end{array}$ & $\begin{array}{l}\text { Duración } \\
5-95 \% \\
\text { (s) }\end{array}$ & $\begin{array}{c}\text { Intensidad } \\
\text { de Arias } \\
(\mathrm{m} / \mathrm{s})\end{array}$ & $\begin{array}{l}\text { Nombre del } \\
\text { sismo }\end{array}$ & Año & Magnitud & $\begin{array}{l}\text { Mecanismo de } \\
\text { falla }\end{array}$ & $\begin{array}{l}\text { Distancia } \\
\text { desde la } \\
\text { falla }(\mathrm{km})\end{array}$ & Vs30 (m/s) \\
\hline 729 & 1.8907 & - & 35.8 & 1.3 & $\begin{array}{l}\text { "Superstition } \\
\text { Hills-02" }\end{array}$ & 1987 & 6.54 & strike slip & 23.85 & 179 \\
\hline 732 & 1.8117 & - & 11.8 & 1.3 & "Loma Prieta" & 1989 & 6.93 & Reverse Oblique & 43.06 & 133.11 \\
\hline 759 & 1.4136 & - & 23.1 & 1.8 & "Loma Prieta" & 1989 & 6.93 & Reverse Oblique & 43.77 & 116.35 \\
\hline 5665 & 1.5769 & - & 45.8 & 1.9 & $\begin{array}{l}\text { "Iwate_Japan" } \\
\text { "El Mayor- } \\
\text { Cucapah_ }\end{array}$ & 2008 & 6.9 & Reverse & 30.38 & 146.72 \\
\hline 5989 & 2.27 & - & 68.9 & 1 & Mexico" & 2010 & 7.2 & strike slip & 40.96 & 162.94 \\
\hline 3965 & 1.1006 & 1.54 & 18.5 & 1.8 & $\begin{array}{l}\text { "Tottori_Japan" } \\
\text { "Parkfield-02_ }\end{array}$ & 2000 & 6.61 & strike slip & 6.86 & 139.21 \\
\hline 4100 & 1.0396 & 1.078 & 7 & 1.6 & $\begin{array}{l}\text { CA" } \\
\text { "Darfield_New }\end{array}$ & 2004 & 6 & strike slip & 1.63 & 173.02 \\
\hline 6959 & 1.3145 & 12.019 & 30.5 & 1.8 & $\begin{array}{l}\text { Zealand" } \\
\text { "Christchurch_ }\end{array}$ & 2010 & 7 & strike slip & 19.48 & 141 \\
\hline 8123 & 0.8507 & 1.554 & 11.2 & 3.6 & New Zealand" & 2011 & 6.2 & Reverse Oblique & 5.11 & 141 \\
\hline
\end{tabular}

Se obtuvieron 16 series de sismos considerando clase de sitio, zona de peligrosidad sísmica y nivel de amenaza sísmica. Se observa que para cada serie, la selección de los registros apuntó a los mayores valores de la ordenada ASI para un determinado valor de la abscisa, buscando también dentro de lo posible contar con una cantidad relativamente uniforme de éstos en los distintos rangos de PGA. Por otro lado, se destaca que para la clase de sitio A solo se contó con 4 registros, razón por la cual no se pudieron obtener las series correspondientes a dicha clase.

\section{CONCLUSIONES}

Este trabajo presentó un procedimiento para seleccionar registros sísmicos compatibles con espectros correspondientes a distintos niveles de amenaza sísmica, con periodos de recurrencia de 500 y 2500 años, para zonas de elevada y muy elevada peligrosidad sísmica de la región del centro-oeste argentino. Un primer desafío abordado fue la obtención de los espectros correspondientes a estos niveles de amenaza sísmica, de 500 y 2500 años de periodo de retorno, a partir de los brindados por el Código de diseño que corresponden a 1000 años de recurrencia. Para ello, se recurrió a antecedentes de normativa internacional actualizada sobre evaluación y rehabilitación sísmica de edificios y puentes y, asimismo, a un estudio reciente de evaluación probabilista del riesgo sísmico para nuestro país. De esa manera, se obtuvieron los coeficientes que relacionan los espectros de respuesta de las recurrencias indicadas. Luego, mediante la utilización de la aplicación web de la base de datos del PEER-NGA y considerando distintos parámetros sismológicos inherentes a la región de estudio, se arribó a un total de 274 registros reales escalados, de los cuales 116 son del tipo impulsivo. Posteriormente, mediante la aplicación de un criterio novedoso, en el cual se contempla la Intensidad de Aceleración Espectral (ASI), se seleccionaron a partir del elenco anterior 16 series de sismos considerando clase de sitio, zona de peligrosidad sísmica y nivel de amenaza sísmica.

A través del proceso de selección utilizado se cumple con la consigna de que los conjuntos de acelerogramas obtenidos toman en consideración la variabilidad o aleatoriedad natural de las características de los movimientos del terreno producidos bajo los posibles escenarios sísmicos en la región de estudio. Con el empleo de estas series de registros representativos de la sismicidad de dicha región podrán obtenerse curvas de fragilidad de mayor confiabilidad para las distintas clases de puentes típicos. 


\section{AGRADECIMIENTOS}

Los autores desean expresar su reconocimiento y, a la vez, agradecer al PEER (Pacific Earthquake Engineering Research Center's) por el desarrollo de la versátil aplicación web utilizada en este trabajo y por facilitar el acceso a la muy valiosa base de datos.

\section{REFERENCIAS}

AASHTO (2011), AASHTO Guide Specifications for LRFD Seismic Bridge Design, American Association of State Highway and Transportation Officials, Washington, DC, 2011.

AASHTO (2018), AASHTO LRFD Bridge Design Specifications, American Association of State Highway and Transportation Officials, Washington, DC.

Aguiar Falconi, R (2004), "Espectros sismicos de riesgo uniforme para verificar desempeño estructural en paises sudamericanos", Boletin Tecnico Universidad Central de Venezuela, pp. 184-186.

ASCE/SEI 7-10 (2010), Minimum Design Loads for Buildings and Other Structures. ASCE/SEI 7-10, American Society of Civil Engineers, Reston, Virginia.

Atkinson G M (2009), "Earthquake Time Histories Compatible with the 2005 NBCC Uniform Hazard Spectrum", N6A 5B7, Dept. Earth Sciences, Univ. of Western Ontario, Canada.

Avsar O (2009), "Fragility Based Seismic Vulnerability Assessment of Ordinary Highway Bridges in Turkey”, $P h D$ Thesis, Middle East Technical University. Ankara, Turquía.

Baker J W (2010), “Conditional mean spectrum: Tool for ground-motion selection”, J. Struct. Eng., Vol. 137, pp. 322-331. DOI: 10.1061/(ASCE)ST.1943-541X.0000215

Baker J W, T Lin, S K Shahi, N Jayaram (2011), "New Ground Motion Selection Procedures and Selected Motions for the PEER Transportation Research Program", PEER Report 2011/03. Pacific Earthquake Engineering Research Center.

Bommer J J y A B Acevedo (2004), "The Use of Real Earthquake Accelerograms as Input to Dynamic Analysis", Journal of Earthquake Engineering, Volume 8, Special Issue 1, pp. 43-92. DOI: $\underline{10.1080 / 13632460409350521}$

Buckle, I, I Friedland, J Mander, G Martin, Nutt, R y M Power (2006), Seismic Retrofitting Manual for Highway Structures: Part 1 -Bridges, Office of Infrastructure Research and Development Federal Highway Administration. Washington DC, USA.

Castano, J C (1992) "Influencia de las fuentes sísmicas potenciales en el diseño sismorresistente". INPRES Publicacion técnica $N^{o}$ 17, pp. 1-20, Instituto Nacional de Prevención Sísmica, San Juan, Argentina.

Cardona O, A Barbat, M Carreño, G Bernal, M Mora, C Velásquez, M Salgado (2016), Perfil de Riesgo de Desastres. Informe Nacional para Argentina, CIMNE, Centro Internacional de Métodos numéricos en Ingeniería. Banco Interamericano de Desarrollo.

Chiou, B S J y R R Youngs (2008), “Chiou-Youngs NGA ground motion relations for the geometric mean horizontal component of peak and spectral ground motion parameters", Earthq. Spectra, Vol. 24, pp. 173-215. DOI: 10.1193/1.2894832

Dhakal R P, J B Mander y N Mashiko (2006), "Identification of Critical Ground Motions for Seismic Performance Assessment of Structures", Earthquake Engineering and Structural Dynamics, Vol. 35, pp. $989-1008$. DOI: $10.1002 /$ eqe. 568 
Elnashai A S, B Borzi y S Vlachos (2004), "Deformation-Based Vulnerability Functions for RC Bridges", Structural Engineering and Mechanics, Volume 17, No. 2, pp. 215-244. DOI: $\underline{10.12989 / \mathrm{sem} .2004 .17 .2 .215}$

FEMA 356 (2000), Prestandard and Commentary for the Seismic Rehabilitation of Buildings, FEMA-356, Federal Emergency Management Agency, Washington, DC, 2000.

FEMA P-751 (2012), 2009 NEHRP Recommended Seismic Provisions: Design Examples, FEMA P-751, National Institute of Building Sciences Building Seismic Safety Council. Federal Emergency Management Agency of the Department of Homeland Security, Washington DC.

FEMA P-58-1(2018), Seismic Performance Assessment of Buildings. Volume 1 - Methodology, FEMA P58-1, Second Edition. Applied Technology Council, Federal Emergency Management Agency.

Frau C y R Saragoni (2005), "Demanda sísmica de fuente cercana. Situación del oeste argentino", Congreso Chileno de Sismología e Ingeniería Antisísmica, IX Jornadas, Concepción, Chile.

Huang D, W Du, H Zhu (2017), "A procedure to select ground-motion time histories for deterministic seismic hazard analysis from the Next Generation Attenuation (NGA) database", Natural Hazards and Earth System Sciences, Vol. 17, pp. 1725-1739. DOI: 10.5194/nhess-17-1725-2017

Huff, T (2016) "Issues in the Prediction of Inelastic Behavior in Bridges during Earthquakes", Practice Periodical on Structural Design and Construction, Volume 21, Issue 3, pp. 13-19. DOI: 10.1061/(ASCE)SC.1943-5576.0000289

INPRES CIRSOC 103 (2018), Reglamento Argentino para Construcciones Sismorresistentes. Parte I. Construcciones en General, Reglamento INPRES CIRSOC 103, Instituto Nacional de Prevención Sísmica, Instituto Nacional de Tecnología Industrial, Argentina.

INPRES-CIRSOC 103 (2019), Proyecto de Reglamento Argentino para Construcciones Sismorresistentes. Parte VI. Puentes de Hormigón Armado, Reglamento INPRES CIRSOC 103, Instituto Nacional de Prevención Sísmica, Instituto Nacional de Tecnología Industrial, Argentina.

Jayaram N, T Lin y J Baker (2011), "A computationally efficient ground-motion selection algorithm for matching a target response spectrum mean and variance", Earthq. Spectra, Vol. 27, pp. 797- 815. DOI: $10.1193 / 1.3608002$

Kempton J J y J P Stewart (2006), "Prediction equations for significant duration of earthquake ground motions considering site and near-source effects", Earthquake Spectra, Vol. 22, No. 4, pp. 985-1013. DOI: $10.1193 / 1.2358175$

Kwon O S y A S Elnashai (2006), "The Effect of Material and Ground Motion Uncertainty on the Seismic Vulnerability Curves of RC Structure", Engineering Structures, Volume 28, pp. 289-303. DOI: 10.1016/j.engstruct.2005.07.010

Luco N y C Cornell (2007), "Structure-specific scalar intensity measures for near-source and ordinary earthquake ground motions”, Earthq. Spectra, Vol. 23, pp. 357-392. DOI: 10.1193/1.2723158

Naeim F y M Lew (1995), "On the use of Design Spectrum Compatible Time Histories", Earthquake Spectra, Volume 11, No. 1, pp. 111-127. DOI: 10.1193/1.1585805

NEHRP Consultants Joint Venture (2011), Selecting and Scaling Earthquake Ground Motions for Performing Response History Analysis, NIST GCR 11-917-15, National Institute of Standards and Technology, Gaithersburg, Maryland.

Nielson B G (2005), “Analytical Fragility Curves for Highway Bridges in Moderate Seismic Zones”, PhD Thesis, Georgia Institute of Technology. Atlanta, Georgia. 
Padgett J E y R DesRoches (2007), "Sensitivity of Seismic Response and Fragility to Parameter Uncertainty", ASCE Journal of Structural Engineering, Volume 133, No. 12, pp. 1710-1718. DOI: 10.1061/(ASCE)0733-9445(2007)133:12(1710)

PEER (2010a), Users Manual for the PEER Ground Motion Database Web Application. Beta version, PEER, Pacific Earthquake Engineering Research Center, University of California, Berkeley.

PEER (2010b), Technical Report for the PEER Ground Motion Database Web Application. Beta version, PEER, Pacific Earthquake Engineering Research Center, University of California, Berkeley.

Priestley M J N, G M Calvi y M J Kowalsky (2007), Displacement-Based Seismic Design of Structures, IUSS Press Istituto Universitario di Studi Superiori di Pavia, Pavia, Italy.

Rix G J y J A Fernandez-Leon (2004), "Synthetic Ground Motions for Memphis, TN" http://www.ce.gatech.edu/research/mae ground motion.

SAC (1997), "Develop Suite of Time Histories - SAC Venture Steel Project Phase 2 Task 5.4.1", http://nisee.berkeley.edu/data/strong_motion/sacsteel/draftreport.html.

Saracho J, G Perez, J Barlek, O Dip, E Castelli (2016), “Clasificación de puentes en Argentina para la evaluación de su vulnerabilidad sísmica”, Tecnología y Ciencia, Año 14, No. 28, pp. 25-37.

Saracho J, G Perez, J Barlek, O Dip, E Castelli (2019), "Evaluación de la vulnerabilidad sísmica de puentes típicos en Argentina a través de análisis dinámico no lineal”, Hormigón y Acero, Vol. 70, No. 288, pp. 57-75. DOI: 10.33586/hya.2019.003

Wang G (2011), "A ground motion selection and modification method capturing response spectrum characteristics and variability of scenario earthquakes", Soil Dyn. Earthq. Eng., Vol. 31, pp. 611625, 2011. DOI: 10.1016/j.soildyn.2010.11.007

Wang G, R Youngs, M Power y Z Li (2015), "Design ground motion library: an interactive tool for selecting earthquake ground motions", Earthq. Spectra, Vol. 31, pp. 617-635. DOI: 10.1193/090612EQS283M

Wen Y K. y C L Wu (2001), "Uniform Hazard Ground Motions for Mid-America Cities", Earthquake Spectra, Vol. 17(2), pp. 359-384. DOI: 10.1193/1.1586179 